\title{
Taxation, Corruption, and Growth*
}

\author{
Philippe Aghion, Ufuk Akcigit, Julia Cagé, and William R. Kerr
}

December 10, 2015

\begin{abstract}
We build an endogenous growth model to analyze the relationships between taxation, corruption, and economic growth. Entrepreneurs lie at the center of the model and face disincentive effects from taxation but acquire positive benefits from public infrastructure. Political corruption governs the efficiency with which tax revenues are translated into infrastructure. The model predicts an inverted-U relationship between taxation and growth, with corruption reducing the optimal taxation level. We find evidence consistent with these predictions and the entrepreneurial channel using data from the Longitudinal Business Database of the US Census Bureau. The marginal effect of taxation for growth for a state at the 10 th or 25 th percentile of corruption is significantly positive; on the other hand, the marginal effects of taxation for growth for a state at the 90th percentile of corruption are much lower across the board. We make progress towards causality through Grangerstyle tests and by considering periphery counties where effective tax policy is largely driven by bordering states. Finally, we calibrate our model and find that the calibrated taxation rate of $37 \%$ is fairly close to the model's estimated welfare maximizing taxation rate of $42 \%$. Reducing corruption provides the largest potential impact for welfare gain through its impact on the uses of tax revenues.
\end{abstract}

Keywords: Endogenous Growth, Taxation, Public Goods, Corruption, Entrepreneurship.

\footnotetext{
${ }^{*}$ Comments are welcome and can be sent to paghion@fas.harvard.edu, uakcigit@uchicago.edu, julia.cage@sciencespo.fr, and wkerr@hbs.edu. Author affiliations are Harvard University, University of Chicago, Sciences Po Paris, and Harvard Business School. We thank Raj Chetty, Jim Davis, the editors and two anonymous referees, and many seminar participants for very helpful comments and suggestions. This research is supported by Harvard Business School, Innovation Policy and the Economy forum, Kauffman Foundation, and University of Pennsylvania. Kerr is a research associate of the Bank of Finland and thanks the Bank for hosting him during a portion of this research. Sina Ates, Alexis Brownell, Karthik Nagarajan, and Jin Woo Chang provided excellent research assistance on this project. The research in this paper was conducted while the authors were Special Sworn Status researchers of the US Census Bureau at the Boston Census Research Data Center (BRDC). Support for this research from NSF grant ITR-0427889 [BRDC] is gratefully acknowledged. Research results and conclusions expressed are the authors' and do not necessarily reflect the views of the Census Bureau or NSF. This paper has been screened to ensure that no confidential data are revealed.
}

(C) 2016. This manuscript version is made available under the Elsevier user license

http://www.elsevier.com/open-access/userlicense/1.0/ 


\section{Introduction}

Is taxation good or bad for growth? A dominant view is that taxation is detrimental to growth. Taxation reduces the reward to entrepreneurial innovation and therefore discourages investments that are important for growth. This perspective emphasizes minimizing the tax burden on successful innovators to encourage more people to try to become successful innovators. An alternative view argues that taxation should not be analyzed independently from the surrounding economic and institutional environment. Taxation, in fact, is central for many aspects of this environment: tax revenues fund public infrastructure, education and schools, legal systems, and much more. Entrepreneurs and innovators often rely heavily on these public goods, and higher taxation can be growth enhancing if it supports the stronger provision of public goods because it raises the expected returns to entrepreneurial efforts. ${ }^{1}$

The overall effects of taxation on growth thus depend upon how taxation's incentive effects weigh against the public goods effects. There are two likely corollaries to this statement. First, the relationship of growth to taxation will likely be non-linear, as the marginal incentive effects and public goods effects will differ greatly depending upon existing taxation levels - the former becoming more painful and the latter becoming less effective as taxation continues to rise. Second, while the incentive effects may be unambiguous, the public goods effect rests on a crucial assumption: that taxes are being spent on public goods and not just inefficiently wasted or appropriated. We would thus anticipate that the optimal taxation rate for a very efficient government will be higher than the optimal rate for the most corrupt. The public good effect presumably explains why some Nordic countries manage to innovate and grow at sustained rates with taxes that are high and highly progressive, while other countries suffer.

This paper takes up this task in three steps. In Section 2, we build an endogenous growth model to analyze how corruption and government efficiency affect the relationship between taxation and growth. Modifying the Klette and Kortum (2004) framework, we build a dependence upon public infrastructure and goods into the innovation and entry process. Taxation revenues can support these public goods, but governments vary in their levels of efficiency. The model predicts an inverted-U relationship between taxation and growth, and the interaction between taxation and corruption has a negative impact on growth to the left of the peak.

In Section 3, we provide empirical evidence on the relationships between taxation, corruption, and economic growth using state- and county-level variations within the United States. Our employment and firm count data are primarily from the Longitudinal Business Database (LBD) of the US Census Bureau. We measure corruption through convictions of local public officials (e.g., Glaeser and Saks 2006), and we collect data on tax revenues from US tax records. Our state-level analysis first considers how lagged tax revenues and corruption influence future growth in state GDP and employment. Over the 1983-2007 period, our panel analysis finds evidence that is consistent with the model's predicted relationships for taxation and corruption on economic growth.

Most important, taxation's marginal impact for growth depends sharply on local corruption. The marginal effect of taxation for growth for a state at the 10th or 25th percentile of corruption is quite positive and robust, and its economic and statistical importance only begins to taper at the upper end of US tax ranges, if at all. On the other hand, the marginal effects of taxation

\footnotetext{
${ }^{1}$ Higher taxation and redistribution may help increase investment opportunities in an economy with imperfect credit markets. For example, see Banerjee and Newman (1993), Galor and Zeira (1993), Benabou (1996), and Aghion and Bolton (1997).
} 
for growth for a state at the 90th percentile of corruption are much lower across the board, and its values are rarely statistically different from zero except at the very lowest levels of initial taxation levels. Even within the limited range of US state income taxes, we see evidence for negative growth effects of increased taxes for states with very high levels of corruption and taxes. By contrast, we find it more difficult to establish effects of corruption for growth beyond this link with taxes in the US context.

Despite using tight empirical specifications with lagged values that predict future growth, a natural worry is that unmodeled factors by state may be driving the connections that we are seeing among taxation, corruption, and growth. To make further progress on these endogeneity issues, we first perform Granger-style tests by regressing past instead of future growth rates on current tax revenues and their interaction with local corruption, and find that the corresponding regression coefficients become insignificant. Then, we turn to county-level patterns. Picking up on the public goods rationale, we develop a circular ring around each county that is 100 miles in radius for our base case. For some counties, this entire ring is still within the county's home state. For other counties, this ring includes parts of other states. We use this ring to develop a localized taxation and corruption level that is specific to each county by taking weighted averages of state-level values that are included in the ring. Taxations and corruption in neighboring states are more strictly exogenous than the behavior of a county's home state. We find that the interaction of corruption and taxation for growth is stronger with these localized levels. Moreover, the localized interaction effects persist when looking at border counties or counties that draw more than $50 \%$ of their weighted taxation and corruption values from states other than their home state. Altogether, these findings give us confidence that the identified link from taxation and corruption to growth is at least partly causal and not the simple product of omitted factors. As we discuss later, our empirical results have important limitations and are far from perfect, but they do shine light on this important question for the United States and emphasize the need for continued study in this area.

Finally, to get a better sense of the importance of corruption on growth and welfare, we calibrate a generalized form of our theoretical model using empirical moments generated from the LBD data. Our list of moments includes key aspects of firm dynamics such as entry, exit, growth, and R\&D intensity. The calibration exercise allows us to derive the optimal tax rate. It also allows us to assess the detrimental impact of corruption on growth and welfare. The calibrated model yields an empirical estimate of the taxation rate of $37 \%$, which is fairly close to the welfare maximizing taxation rate of $42 \%$. More interestingly, removing corruption fully from the calibrated solution results in a consumption equivalent gain of more than $20 \%$, which is quite important in size. The calibration strongly suggests that the most substantial growth impacts can emerge from reduced corruption and more efficient government, with optimal tax calibration at our current efficiency levels being second-order.

This paper relates to a whole body of literature on taxation, incentives, corruption, and growth. Representative studies include Helms (1985), Barro (1990, 1991), Mofidi and Stone (1990), Barro and Sala-i-Martin (1995), Mauro (1995, 1998), Fisman and Gatti (2002), Gordon and Lee (2007), Straub (2008, 2011), Hassett and Mathur (2008), and Hauner and Kyobe (2010). The literature on how entrepreneurship and investment are impacted by taxation includes Gentry and Hubbard (2005), Petrescu (2009), Djankov et al. (2010), Rohlin et al. (2010), and Nanda (2011). Public investment and economic growth are discussed by Aschauer (1989), Calderon and Serven (2004), Singhal (2008), and Chakraborty and Dabla-Norris (2011). 
Tanzi and Davoodi (2000) and Romp and de Haan (2007) provide comprehensive discussions of the interlinkages among corruption, public finances, and economic development and growth. Prior work also describes how corruption can weaken the public goods necessary for growth (e.g., Del Monte and Papagni 2001, 2007; Paserman et al. 2008, Fiorino et al. 2012), with Italian regional variation being frequently exploited. Our work differs from this prior literature in its efforts to build these factors into an endogenous growth model and then empirically characterize the marginal growth implications across the US taxation-corruption distribution. This joint distribution provides a much richer portrait of how taxation's effects are realized. The calibrated model also allows us to provide a micro-founded assessment of optimal taxation levels given this trade-off. We hope this framework is useful to other researchers approaching this important policy choice. ${ }^{2}$

\section{Theoretical Model}

We develop a Schumpeterian growth model of the relationship between taxation, corruption or government efficiency, and growth/innovation. This section outlines the structure of the baseline model where we abstract from physical capital in the model. In a later section, we generalize the model by introducing capital and then calibrate it to the US data. Proofs and detailed mathematical derivations are contained in the appendix. Our model contains qualityimproving innovations that generate growth due to the actions of entrants and incumbents. More specifically, it builds on Klette and Kortum (2004) the additional feature that the innovation production function depends on the quality of the infrastructure of the economy, which is provided by the government through taxation. This framework has the attractive feature of allowing simultaneous study of new entrants with the innovative behavior of multi-product incumbent firms. Variations in government corruption and efficiency impact the quality of the infrastructure provided per tax dollar, and thus economic growth. ${ }^{3}$

\subsection{Basic Environment}

\subsubsection{Preferences}

Consider the following continuous time model. The economy consists of a representative household with preferences over consumption and leisure

$$
U=\int_{0}^{\infty} e^{-\rho t}\left(\ln C_{t}-L_{t}\right) d t
$$

\footnotetext{
${ }^{2}$ Our model builds on the existing innovation-based growth literature (Romer 1986, 1990, Aghion and Howitt 1992, and Klette and Kortum 2004). See also Acemoglu (2009) and Aghion and Howitt (2009) for recent overviews of that literature. Recent theoretical and empirical links of entry dynamics to economic growth includes Acs and Armington (2006), Aghion et al. (2007), Akcigit and Kerr (2010), Acemoglu et al. (2011), Haltiwanger et al. (2013), and Glaeser et al. (2015). Our work also connects to a literature on the determinants of spatial location (e.g., Marshall 1920, Rosenthal and Strange 2004, Duranton and Puga 2004, Glaeser 2008, Ellison et al. 2010). This work often emphasizes both theoretically and empirically taxation and the strength of public goods. Finally, our paper connects to the allocation of talent and growth (e.g., Baumol 1990, Murphy et al. 1991, Banerjee and Newman 1993).

${ }^{3}$ Our model has a fixed population of workers and thus differs from tax competition frameworks that model increased business movements to jurisdictions with more favorable environments. Our empirical work below considers these shifts as well.
} 
where $C_{t}$ is the consumption of the unique final good and $L_{t}$ is the labor supply by the household. Labor can be used in four ways: production of the final good $L_{P}$, innovation in incumbent firms $L_{I}$, innovation in entrants $L_{E}$, and government workers to provide infrastructure $L_{G}$.

The household owns a balanced portfolio of all the firms in the economy, therefore its budget constraint is

$$
C_{t}+\dot{A}_{t}=w_{t} L_{t}+r_{t} A_{t}+\beta T_{t},
$$

where $w_{t}$ is the wage, $r_{t}$ is dividend payment from the asset holdings, $\dot{A}_{t}$ is the new investment in assets, and $T_{t}$ is the tax revenue collected by the government. We normalize the price of the final good to $P_{t}=1$ without loss of generality.

\subsubsection{Production Technology}

The unique final consumption good $Y_{t}$ is produced using capital $K_{t}$ and the basket of intermediate varieties $Z_{t}$ according to the CRS production function

$$
Y_{t}=K_{t}^{\xi} Z_{t}^{1-\xi}
$$

In this section, we abstract from capital by assuming $\xi=0$ (hence $Y_{t}=Z_{t}$ ). This means that final good is produced only through the intermediate goods basket $Z_{t}$ which itself is produced using the CES aggregator

$$
\ln Z_{t}=\int_{0}^{1} \ln z_{t}(i) d i .
$$

In this expression, $i$ indexes a unique product line. Firms in the same product line compete a la Bertrand, so only the latest innovator is active in equilibrium. Each intermediate variety is produced using labor only according to the linear production technology

$$
z_{t}(i)=q_{t}(i) l_{t}(i)
$$

Thus, the constant marginal cost of production is

$$
M C_{t}(i)=\frac{w_{t}}{q_{t}(i)} .
$$

Each innovation improves the productivity of a given line $i$ from $q_{t}(i)$ to $(1+\lambda) q_{t}(i)$. A firm in this economy is defined by a collection of product lines. In equilibrium, the number of product lines summarizes the state of a firm. We denote the number of product lines of an incumbent firm by $n \in \mathbb{Z}_{+}$. A firm exits the economy and becomes an outsider when $n=0$.

\subsubsection{Innovation Technology}

Firms obtain new product lines through innovation. Acquiring product lines contributes to firm value by increasing firm profits. Firms hire $L_{I}$ innovation workers to generate a Poisson flow rate of new innovations. Infrastructure in the economy and firm-specific knowledge stock complement labor in the innovation production. In particular, the innovation flow $I$ is generated according to

$$
I=\alpha_{t} n^{1-\gamma}\left(\frac{L_{I}}{\gamma}\right)^{\gamma}
$$


where $n$ is the firm's stock of existing product lines (the firm-specific knowledge stock) and $\alpha_{t}$ is the quality of the economy's infrastructure. After a small time interval $\Delta t$, a firm $f$ invents a new product with probability $I \Delta t$. Innovations are undirected, and a successful innovation is realized throughout the unit interval $[0,1]$ with equal probability. When firm $f$ innovates in product line $j$, two things happen. First, the innovating firm obtains the new product line $j$ and therefore its number of product lines increases from $n$ to $n+1$. Second, the technology in $j$ increases by the step size $\lambda$.

For the sake of tractability, we will assume $\gamma=1 / 2$. Then the innovation production function (4) generates the following innovation cost function

$$
C(I, n)=w_{t} L_{I}=w_{t} \frac{n}{2}\left(\frac{x}{\alpha_{t}}\right)^{2}=n c(x),
$$

where $x \equiv I / n$ is the innovation intensity.

\subsubsection{Infrastructure and Government}

The economy's infrastructure (broadly defined) aids the innovation efforts of firms. The stock of infrastructure $\alpha_{t}$ depreciates at the rate $\delta_{\alpha} \in(0,1)$ at every instant. The government invests $F_{t}$ in new infrastructure through money derived from taxation. As a result, the law of motion for the infrastructure can be expressed as

$$
\dot{\alpha}_{t}=-\delta_{\alpha} \alpha_{t}+F_{t}
$$

The government hires $L_{G t}$ workers to produce $F_{t}$ units of infrastructure with a one-to-one technology

$$
F_{t}=L_{G t} .
$$

The government taxes firm operating profits (net of innovation expenses) $\Pi_{t}$ at the rate $\tau \in$ $[0, \bar{\tau}]$. Tax revenue $T_{t}$ is subject to corruption at a fraction $\beta \in(0,1)$. As a result, only $(1-\beta)$ fraction of the tax revenue turns into government investment

$$
F_{t}=\frac{(1-\beta) T_{t}}{w_{t}},
$$

where $T_{t} \equiv \int_{0}^{1} \tau_{t} \Pi_{t}(i) d i$. The same amount of tax payers' money turns into better infrastructure if the government is more effective. Corrupted money $\beta T_{t}$ is added to the household budget as a corruption income. The resource constraint is $Y_{t}=C_{t}$, with all expenses in terms of labor units. ${ }^{4}$

\subsubsection{Entry and Exit}

There is a mass of potential entrants into the intermediate sector of the economy. They generate a flow rate $\tilde{x}$ of new innovations by hiring $L_{E}$ innovation workers according to

$$
\tilde{x}=\alpha_{t} \phi L_{E}
$$

\footnotetext{
${ }^{4}$ The generalized model in Section 4 adds capital investment to the resource constraint.
} 
where $\phi$ is a constant entry cost parameter. When an outsider innovates, it captures a new product line that has value $V_{t}$ defined below. Therefore the value of an outsider $V^{\text {out }}$ can be written as

$$
r V^{\text {out }}=\max _{\tilde{x}}\left\{-\frac{w_{t}}{\phi \alpha_{t}} \tilde{x}+\tilde{x}\left[V_{t}-V^{\text {out }}\right]\right\} .
$$

This value function captures the instantaneous flow cost $\left(w_{t} / \phi \alpha_{t}\right) \tilde{x}$ of attempting to enter the market and the change in the outsider's value $V_{t}-V^{\text {out }}$ upon success, which happens at the rate $\tilde{x}$. An incumbent firm joins the pool of outsiders when it loses all of its product lines and obtains the value $V^{\text {out }}$.

\subsection{Equilibrium}

Our focus will be on balanced growth path equilibrium. All equilibrium values will be denoted by an asterisk "*". Henceforth we will drop the time subscripts.

Definition 1 A balanced growth path equilibrium (BGP) of this economy consists of constant prices $\left(r^{*}, w^{*}\right)$, a constant value of incumbent firms $V(n)$, constant incumbent firm innovation $I^{*}(n)$ and entrants' innovation $\tilde{x}^{*}$ yielding the destruction rate $\mu^{*}$, constant infrastructure level $\alpha^{*}$, constant government investment $F^{*}$, constant tax rate $\tau$ and the allocation $\left\{Y^{*}(t), C^{*}(t), L^{*}, L_{P}^{*}, L_{I}^{*}, L_{E}^{*}, T,\left\{y_{i}^{*}(t), l_{i}^{*}\right\}_{i \in[0,1]}\right\}_{t \geqslant 0}$ with the price sequence $\left\{p_{i}^{*}(t)\right\}_{i \in[0,1], t \geqslant 0}$ such that $(i) p_{i}^{*}, y_{i}^{*}$, and $l_{i}^{*}$ maximize incumbent firm (operational) profit for each $i$ and $t,(i i)$ innovation decisions $I^{*}(n)$ and $\tilde{x}^{*}$ maximize the incumbent and entrant firm values, respectively, with the outside firm value being $V^{\text {out }}=0$, (iii) households maximize their utility given the prices $\left(r^{*}, w^{*}\right),(i v) w^{*}$ and $r^{*}$ are compatible by household optimization, $(v) \alpha^{*}$ evolves following (5), (vi) $F^{*}$ satisfies (6), (vii) $L^{*}, L_{P}^{*}, L_{I}^{*}, L_{E}^{*}$, and $L_{G}^{*}$ satisfy market clearing given $w^{*}$, and (viii) the resource constraint satisfies $Y_{t}^{*}=C_{t}^{*}$.

Next we will solve for the balanced growth path equilibrium. From the household's problem, we can express the Hamiltonian as $H=\ln C-L+\mu[w L+r A+\beta T-C-\dot{A}]$, which delivers the equalities

$$
g=r-\rho \text { and } w^{*}=C=Y .
$$

Next we turn to the monopolist's problem. Since the final goods production function is CRS Cobb-Douglas, and since factors are paid their marginal product, Euler's theorem implies that expenditure on intermediates is $P_{t} Z_{t}=Y_{t}$. Furthermore, logarithmic aggregation of intermediates implies that expenditure on each variety is the same. Therefore, demand for variety $i$ is given by:

$$
z_{t}(i)=\frac{Y_{t}}{p_{t}(i)}
$$

Bertrand limit pricing in each product line $i$ implies that the current innovator firm prices at the marginal cost of previous innovator (i.e., $p_{t}(i)=(1+\lambda) w_{t} / q_{t}(i)$ as the previous owner's technology level is $\left.q_{t}(i) /(1+\lambda)\right)$ and therefore

$$
p_{t}(i)-M C_{t}(i)=\frac{\lambda w_{t}}{q_{t}(i)}
$$


So monopolist profits are

$$
\pi_{t}^{*}=Y_{t} \frac{\lambda}{\lambda+1}
$$

We choose the parameters such that $(i)$ firms generate positive profits in equilibrium and $(i i)$ the maximum possible tax level $\bar{\tau}$ is sufficiently large that one can generate a non-monotonic relationship between taxation and growth.

Assumption 1 Parameters of the model are such that the operating profit is positive for all tax rates and the upper limit of the maximum tax rate is sufficiently large, i.e.,

$$
1>\frac{1+\lambda}{2 \lambda[1-\bar{\tau}]^{2} \phi^{2}}>\frac{1-2 \bar{\tau}}{1+2 \bar{\tau}} .
$$

To solve for the optimal innovation decisions, we express the Hamilton-Jacobi-Bellman equation for an $n$-product incumbent firm. Let $\mu^{*}$ denote the aggregate equilibrium innovation rate in the economy. Since each of the product lines will be lost to a competitor at this flow rate, the value function of a firm with $n$ product lines is written as

$$
r^{*} V_{t}(n)-\dot{V}_{t}(n)=\max _{x}\left\{\begin{array}{c}
{[1-\tau]\left[n \pi_{t}^{*}-w_{t} \frac{n x^{2}}{2 \alpha^{2}}\right]} \\
+x n\left[V_{t}(n+1)-V_{t}(n)\right] \\
+\mu^{*} n\left[V_{t}(n-1)-V_{t}(n)\right]
\end{array}\right\} .
$$

This value function takes an intuitive form. The instantaneous safe return on the left-hand side is equal to the risky expected return on the right-hand side. The first term on the right is the after-tax operating profit of a firm that generates a gross profit of $n \pi_{t}^{*}$ and pays an innovation cost of $n w_{t}\left[x^{2} / 2 \alpha^{2}\right]$ every instant. The firm innovates at rate $x n$, in which case its value increases by $V_{t}(n+1)-V_{t}(n)$. Similarly, the firm loses a product at rate $\mu^{*} n$, in which case the change is simply $V_{t}(n-1)-V_{t}(n)$.

Since the firm problem is scales up linearly with firm size, the following lemma holds.

Lemma 1 The value function $V_{t}(n)$ is linear in $n$ and $Y_{t}$ such that $V_{t}(n)=v^{*} n Y_{t}$, where $v^{*}>0$ is a constant. Moreover the optimal innovation decision is $x^{*}=\alpha^{2} v^{*} /[1-\tau]$.

Next, we turn to the entrant's problem. We will have an equilibrium with positive entry if $w_{t}=\phi\left[v^{*} Y_{t}-V_{t}^{\text {out }}\right] \alpha$. When there is positive entry, an outsider's value is simply $V^{\text {out }}=0$ and $1 / \phi \alpha=v^{*}$. Therefore,

$$
v^{*}=\frac{1}{\phi \alpha^{*}} \text { and } x^{*}=\frac{\alpha^{*}}{[1-\tau] \phi} .
$$

Along the BGP, infrastructure $\alpha^{*}$ and government investment $F^{*}$ are constant. From the law of motion, $F^{*}=\delta_{\alpha} \alpha^{*}$ in steady state. Then the balanced budget in (7) gives

$$
F^{*}=(1-\beta) \tau \Pi^{*},
$$

where $\Pi^{*} \equiv \lambda /(1+\lambda)-1 / 2 \phi^{2}(1-\tau)^{2}$ is the equilibrium operating profit. Note that the equilibrium operating profit is decreasing in the tax rate $\tau$ which highlights the disincentive effect of taxation. The equilibrium level of infrastructure is

$$
\alpha^{*}=\frac{(1-\beta) \tau \Pi^{*}}{\delta_{\alpha}} .
$$


The government sustains a lower infrastructure in equilibrium if corruption or depreciation is high. The effect of the tax rate on the equilibrium level of infrastructure is non-monotonic.

The entrant's innovation rate is determined from the optimal values (11) and the value function (10),

$$
\tilde{x}^{*}(\tau)=\phi(1-\tau) \alpha^{*} \Pi^{*}-\rho .
$$

Overall, the aggregate innovation rate $\mu^{*}=x^{*}+\tilde{x}^{*}$ from (11) and (14) is

$$
\mu^{*}=\frac{\alpha^{*}}{(1-\tau) \phi}+(1-\tau) \phi \alpha^{*} \Pi^{*}-\rho .
$$

Then, using the fact that the aggregate growth rate is

$$
g^{*}=\mu^{*} \ln (1+\lambda),
$$

we easily obtain:

Proposition 1 For any given level of government effectiveness $\beta$, the effect of an increase in the tax rate has an inverted- $U$ effect on equilibrium growth,

$$
\frac{\partial g^{*}}{\partial \tau}=\left\{\begin{array}{l}
>0 \text { for } \tau<\tau_{g} \\
=0 \text { for } \tau=\tau_{g} \\
<0 \text { for } \tau>\tau_{g}
\end{array} .\right.
$$

Moreover, the positive impact of tax on growth is smaller if the government is less effective (when $\beta$ is higher)

$$
\frac{\partial^{2} g^{*}}{\partial \tau \partial \beta}<0 \text { for } \tau<\tau_{g}
$$

In words: (i) aggregate growth rate is determined by the rate of new innovation arrivals $\mu^{*}$ and the size of their contributions $\ln (1+\lambda)$; (ii) taxation and corruption impact innovation efforts and thereby the arrival rate of new innovations; (iii) while taxation discourages innovation through reducing ex-post rents, it also encourages innovation and growth through better provision of infrastructure; (iv) taxation contributes to growth initially as there has to be at least some government revenue to be able to provide the necessary infrastructure in the economy; however, excessive taxation deters ex ante innovation by reducing the ex-post profits $\Pi^{*}$ too much; (v) the higher the degree of corruption, the lower the potential contribution of a tax dollar on the economy since less of this tax revenue will go into infrastructure.

Finally, one can look at the effects of taxation and corruption on equilibrium entry and on the size distribution of firms. One can first establish:

Proposition 2 For any given level of government effectiveness $\beta$, the effect of an increase in the tax rate has an inverted- $U$ effect on the entry rate,

$$
\frac{\partial \tilde{x}^{*}}{\partial \tau}=\left\{\begin{array}{l}
>0 \text { for } \tau<\tau_{\tilde{x}} \\
=0 \text { for } \tau=\tau_{\tilde{x}} \\
<0 \text { for } \tau>\tau_{\tilde{x}}
\end{array}\right.
$$

where the cutoff is implicitly defined as $\frac{1+2 \tau_{\tilde{x}}}{\left(1-2 \tau_{\tilde{x}}\right)\left(1-\tau_{\tilde{x}}\right)^{2}}=2 \pi^{*} \phi^{2}$. 


\section{Empirical Analysis}

We now provide empirical evidence on the impact of income taxation and corruption on economic growth using panel variation across states and counties within the United States over a 25-year period. We first describe the data assembled and our econometric strategy. We then consider state-level analyses of economic growth. We close this empirical section with a state-border analysis that uses county-level data and possesses attractive inference properties outlined below. In the next section, we consider a calibrated form of the model to provide more-structured quantitative evidence.

\subsection{Data Structure}

Our starting point is to empirically examine whether patterns of state-level economic growth for the United States are consistent with our model's emphasis on the interaction between taxation and corruption. We consider these issues using state-level variations in the United States for several reasons. First, metrics like taxation and corruption are notoriously difficult to compare across countries, and by focusing on state-level experiences we have greater confidence for an apples-to-apples comparison. This approach also allows us to better isolate our taxation and corruption interests from other national features (e.g., trade reforms, stock market booms), although we must remain diligent for other state-level factors connected to growth. Second and related, our econometric strategy utilizes a panel analysis to push the achieved level of identification as far as possible. Such a panel analysis requires a sufficiently long data span to measure fixed effects for spatial units, and US data provide this necessary panel length in addition to their homogeneous measurement.

Typical of endogenous growth frameworks, the focus of our model and upcoming numerical calibrations is GDP per worker, and we accordingly devote extra attention to this particular outcome in our empirical work. An empirical analysis using regional variations, however, can also encounter another form of growth through the spatial movement of activity towards places with improving attributes. Indeed, many varieties of the spatial equilibrium model from the urban literature (e.g., Glaeser 2008) require real wages be fixed over cities, thus forcing adjustments over cities to occur via population changes to keep the spatial equilibrium. In more practical terms, the business press frequently connects a state's business climate to its ability to attract firms and workers from other states, which is not present in an endogenous growth model with fixed populations. We thus complement our model's growth in GDP per worker with a broader set of metrics that include growth in GDP, workers, establishment counts, and so on. We also consider drivers connected to growth like entry/exit, patenting, etc. Our goal is to provide a broad and robust depiction of these novel patterns, even where they extend beyond the model, to establish a comprehensive perspective.

We collect estimates of state GDP from the Bureau of Economic Analysis (BEA). We draw our employment and establishment data from the Census Bureau's Longitudinal Business Database (LBD). The LBD is the business registry for the United States and contains annual observations for every private-sector establishment with payroll from 1976 onward. Sourced from US tax records and Census Bureau surveys, the micro-records document the universe of establishments and firms rather than a stratified random sample or published aggregate tabulations. Jarmin and Miranda (2002) describe the LBD construction. As a representative year, the data include 108 million workers and 5.8 million establishments in 1997. This data 
platform provides great flexibility for disaggregating employment growth effects into separate parts.

Our empirical estimations consider the 1983-2007 period, and we structure our data into five-year time periods that run from 1983-1987 to 2003-2007. ${ }^{5}$ Within each time period, we take the average of our economic variables like GDP and employment. We believe that these fiveyear periods provide us the best time horizons for measuring the medium-term growth impacts from taxation and corruption. Most estimations focus on 46 states and the District of Columbia that have non-zero state income taxes throughout the period studied. The four excluded states are Nevada, Texas, Washington, and Wyoming. We have conducted an extensive number of tests regarding these states and find very similar results if we incorporate them in some manner (e.g., assigning them the lowest possible value of income tax revenue per government expenditures observed in their region over the corresponding period). We occasionally exclude Alaska and Hawaii when modelling covariates due to data limitations.

Table 1 provides the mean and standard deviation of metrics across observations. States average $\$ 167$ billion in annual economic activity over the period studied (for a sample total of almost $\$ 8$ trillion), and the average GDP per worker is about $\$ 70,000$. In a typical year, the average state has 2.3 million workers (for a sample total of 108 million workers). About one-quarter of these workers are typically in young establishments, which we define to be establishments aged four years or less. Around one in ten workers in a given year is employed in an entering or exiting establishment. The average state has 120,000 establishments with an average employment size of 21 workers. We measure log growth across the five-year periods of our data structure, and we winsorize growth rates at their $1 \%$ and $99 \%$ levels to guard against outliers. Five-year growth rates average about $5 \%$ for deflated state GDP per worker and 7\%-8\% for employment and establishment growth.

We next describe our measures of state taxation and corruption. State income taxation comes from the BEA and averages $\$ 3$ billion in annual revenues. We use a combined measure of corporate and personal income tax given the equivalence for many small businesses that are "pass-through entities" (e.g., sole proprietorships, limited liability corporations). As described further below, our empirical work normalizes state income tax revenues by initial government expenditures in the state. This share averages $16 \%$, recognizing that the denominator is funded to a substantial degree by federal transfers and states can run unbalanced budgets. The most substantial part of state taxation not included in our analysis is state sales tax.

The final row of Panel A provides our corruption metric. This is the most difficult data piece to measure from a conceptual perspective, as the efficiency with which tax revenues are translated into useful infrastructure can be dampened by factors beyond overtly corrupt behavior (e.g., incompetence, laziness). While some think tanks are now "grading" states on their effectiveness of government, these report cards are only very recent and do not offer a long history to analyze. We follow prior work by considering federal convictions of corrupt public officials by state. These data are collected and published by the Public Integrity Section of the Department of Justice for 93 districts, including some US territories like Guam and Puerto Rico, which we aggregate to states. ${ }^{6}$ The corruption cases include local, state, and federal officials and stretch back to the 1970s. There are some instances of unreported conviction

\footnotetext{
${ }^{5}$ For most employment-related outcomes, the last period is calculated over 2003-2005 due to LBD data releases, although we have confirmed our aggregate employment effect across the full 2003-2007 period using County Business Patterns.

${ }^{6}$ United States Department of Justice (Public Integrity Section): http://www.usdoj.gov/criminal/pin/.
} 
totals for small districts in a given year, and we code these and zero convictions to be a single conviction minimum. These choices are not very important as the major bouts of corruption can see a district jump from 4-5 cases per year to over 50. Measures of convictions are not perfect, especially as they do not reflect the legal but damaging ways that tax money could end up being diverted from productive uses (e.g., the proverbial "bridge to nowhere"), but they are the best available options given their long history and impartial measurement across states. The average state has 18 convictions per annum.

Panel B of Table 1 provides county-level data, with the levels and growth rates of LBD activity aligning with the state data in Panel A. We describe later the shares of counties on state borders.

\subsection{Econometric Strategy}

Our basic empirical specification takes the form

$$
\begin{aligned}
Y_{s, t}= & \beta_{1} \ln \left(\text { tax }_{s, t-1}\right)+\beta_{2}\left[\ln \left(\operatorname{tax}_{s, t-1}\right)\right]^{2}+ \\
& \gamma \ln \left(\text { corruption }_{s, t-1}\right)+ \\
& \chi_{1} \ln \left(\text { tax }_{s, t-1}\right) \cdot \ln \left(\text { corruption }_{s, t-1}\right)+ \\
& \chi_{2}\left[\ln \left(\text { tax }_{s, t-1}\right)\right]^{2} \cdot \ln \left(\text { corruption }_{s, t-1}\right)+\phi_{s}+\eta_{t}+\epsilon_{s, t},
\end{aligned}
$$

where $\phi_{s}$ and $\eta_{t}$ are state and period fixed effects, respectively. The variable $\operatorname{tax}_{s, t-1}$ is the average income tax revenues collected in the previous five-year period converted into constant 2000 dollars. The variable corruption ${ }_{s, t-1}$ is the average number of officials convicted of crimes in the previous period. The final terms interact the tax variables with the corruption measure.

Our two main regressor variables are normalized by a time-invariant measure of state size. Our reported specifications use average government expenditures in the state from the initial period as the measure of state size, and we find similar results using other state size measures such as initial state employment or GDP. With the log specification, this normalization choice only impacts the estimation through the interaction effect, and the added baseline provides a relative sense of the magnitude of the tax or corruption changes for interaction. Similar to our growth metrics, we winsorize our explanatory variables at their $1 \%$ and $99 \%$ values.

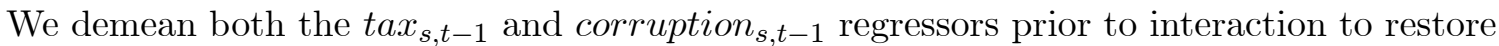
their main effects. We thus anticipate a positive $\beta_{1}$ coefficient and negative $\beta_{2}$ coefficient. This coefficient pattern would suggest an inverted-U shape to marginal tax effects: at the mean value of corruption, increases in lagged tax revenues are associated with increases in the outcome variables $Y_{s, t}$ so long as taxes are not too high. As we return to later, both in our empirical work and in our calibration, the state-level variation that exists in the United States appears to be mostly, if not fully, contained on the left-hand side of any inverted-U, which may limit the precision with which we can measure the curvature.

We also anticipate a negative $\gamma$ coefficient as increases in lagged corruption, everything else equal, should decrease future economic activity. Finally, we anticipate negative $\chi_{1}$ and $\chi_{2}$ coefficients: higher corruption should weaken any positive taxation effects, and this discouragement should be particularly strong when taxes and corruption are very high. Negative interaction effects would suggest that periods of high tax revenues per capita, which have the capacity to promote unmeasured public goods when used correctly, were not followed by better growth in states that were particularly corrupt during the period. In many respects, we 
concentrate most on the presence of a negative $\chi_{1}$ given the central importance in our theory of the interaction between taxation and corruption.

There are several potential challenges to this econometric strategy that we should note. First, we have standard omitted variable bias questions about whether our model captures all of the relevant growth factors necessary for teasing out the roles of taxation and corruption. These concerns are our central motivation for pursuing first and foremost panel analyses that allow us to control for persistent state traits connected to economic growth over the last three decades (e.g., warm climate, right to work laws). To bias our estimates, this approach requires that the missing factors move in a correlated manner with our explanatory variables, which is a first but crucial defense, and we also test directly for robustness to other state-level factors below. Of course, the flip-side of this controlled platform is that we are measuring relationships through deviations from means for states, which could be transient and mean reverting, and so we also consider below less-structured approaches as well.

Second, we face difficult questions about reverse causality. Corruption can be exogenous or endogenous. An example of the former, from the perspective of our study, is simply the unexpected "bad apple" politician who starts to behave corruptly without new economic conditions to prompt the behavior. The more-worrisome endogenous channel for our work would be where a change in growth prospects or economic conditions for a region give rise to the corruption itself. This reverse channel could work equally for or against finding the anticipated negative effect. It could be, for example, that heightened growth prospects give more scope for corruption to occur (e.g., demand for regulatory approvals give rise to bribery); it could alternatively be that declining growth prospects of a state shift activity towards corruption as rent seeking becomes the most productive way to make money (e.g., Baumol 1990).

We have two main routes to assess whether the results that we observe are due to reverse causality. The first is to consider the timing of variables, and specification (17) models lags of explanatory variables. As a pseudo Granger test of causality, we test reversing this timing and model whether forward explanatory variables predict current growth. Our results generally confirm that the timing of corruption versus growth consequences is more in line with the theory laid out rather than the reverse.

The second route is to study settings where we believe the corruption that is impacting economic outcomes is more exogenous in terms of not being the focus of the corrupt politician. This concept is built into our state-border analysis using county-level data. The core idea is expressed in the Florida panhandle, although there are many geographic examples of this form. Counties in the Florida panhandle can be substantially influenced by the functioning of the counties in Alabama and Georgia that share the border with them. The bordering counties are influenced by the corruption/effectiveness of activity in the state capitals located in Montgomery and Atlanta, which are respectively about 100 and 250 miles from the closest border point with Florida. Our identifying assumption for this work is that the corruption levels in these state capitals are being made without strong reference to these border counties, but that they can still matter (e.g., due to misappropriation of highway funds that impact roads throughout the state). As we pick up in more detail later, we confirm our results in such settings to provide reassurance against reverse causality being the factor behind our outcomes. 


\subsection{State-Level Results}

Tables $2 \mathrm{a}$ and $2 \mathrm{~b}$ consider the log of state GDP as the left-hand variable $Y_{s, t}$. In the presence of the state fixed effects $\phi_{s}$, these estimations measure how changes in the income taxation and corruption levels of a state correlate to subsequent expansions in economic activity. This is the simplest test of Propositions 1 and 2, where better business environments are predicted to increase the rate of new innovation arrivals that engender growth. After studying these levels estimations, we turn to whether the effects are powerful enough to measure statistically significant accelerations in growth rates, which are the stronger predictions of the model. The regressions have 188 observations from the cross of 47 states and four time periods. We cluster standard errors by state.

Column 1 of Table 2a begins with a simpler model than specification (17) where we drop the squared values for taxation. This estimation shows a very stable and well-defined pattern. The $\beta_{1}$ coefficient for income taxation revenues is positive and statistically significant, the $\gamma$ coefficient for corruption is negative but not economically nor statistically important, and the $\chi_{1}$ interaction of corruption and taxation is negative and statistically significant. We provide shortly an interpretation of the joint size of the results and, for now, focus on their stability. We weight our baseline specifications by the initial employment count in the state to provide a sense of mean treatment effects. Column 2 shows similar results when excluding these sample weights, although the interaction falls just short of statistical significance due to the larger standard errors. Sample weights tend to focus attention on better quality data as very small states are more likely to show outlier behaviors, but the results are overall quite comparable in unweighted formats.

Columns 3 and 4 incorporate region $\mathrm{x}$ period fixed effects to capture broad differences across areas of the United States in terms of their pace of growth, corruption, and so on. As a very noticeable example, much of US growth during the last three decades has been in warmer and sunnier cities in the South and West, compared to the Northeast and Midwest. Column 3 models four large Census regions, while Column 4 models nine Census divisions. The main effect of taxation in Column 4 is sensitive to including period fixed effects interacted with the nine census divisions, but otherwise the results are extremely stable, which is encouraging given the different stress tests performed. The region-period fixed effects help confirm that our results are not due to differential growth trends across the United States.

Column 5 tests introducing controls for time trends interacted with the traits of states in 1987, at the start of our sample period. We measure for states their initial log levels of population, patenting (reflective of $R \& D$ investments), and high-school educated workers. We interact these baseline levels with a trend for years and introduce these three controls into the specification. The state fixed effects control for the initial traits, while the period fixed effects control for common time effects. If anything, these controls sharpen our estimation further, suggesting that the growth results are not capturing ongoing trends in these modelled factors. It is worth noting, however, that we do not find consistent results when taking this approach to an extreme and modelling separate time trends for each state. Given that we only have four observations per state, this latter sensitivity is anticipated if also disappointing, and we must stop at modelling factors directly.

Column 6 considers whether the estimated effects are descending from a single block of states in the tax distribution behaving in a uniform manner. One example of this could be lower-tax states persistently lagging as a group the performance of higher-tax states; a second 
example might be states in the middle of the tax distribution consistently targeting taxation breaks and subsidies to lure firms from high-tax neighbors, which would be comparable to the findings of Wilson (2009) for R\&D tax breaks at the state level. To test for these types of concerns, we group states by their initial taxation levels into quartiles. We then include quartile $\mathrm{x}$ period fixed effects that require the identifying variation to be within these groups. The results are robust to this control, providing comfort that our findings are not due to one particular block of states in terms of taxes behaving in a uniform manner to give us an inflated sense of precision. We likewise find this robustness when allowing assignment to tax quartiles to be time varying or when using terciles/halves.

The results further hold up well when including lagged state GDP in Column 7, and we similarly find consistent results when dropping the state fixed effects and modelling just a single control for initial state GDP. In both cases, the main effects for taxation weaken somewhat, while the interaction effect remains very strong. We have further confirmed that our results are not dependent upon any one state or time period being included in the sample.

Column 8 includes the squared terms present in specification (17). The results here are mixed. On one hand, the point estimates for $\beta_{2}$ and $\chi_{2}$ are negative, indicative of the inverted$\mathrm{U}$ shape present in theory. Moreover, the economic magnitudes implied are of reasonable economic size, as we map out further in Table $2 \mathrm{~b}$. To give a rough sense, holding corruption fixed at the US median, moving from the 25 th to 75 th percentile of state income tax levels (the interquartile range) is associated with an $18 \%$ reduction in the positive connection between GDP expansion and taxation. At the 90th percentile of corruption, this implied reduction across the interquartile range is $40 \%$. On the other hand, the squared terms are not statistically significant ( $\beta_{2}$ is close) and the overall curvature quantified by these estimates means that we are measuring all effects on the left-side portion of the curve where taxes and growth are positively related given US conditions.

We next calculate the "marginal effects" for GDP expansion for an income tax or corruption increase at various points in the taxation-corruption distribution. We place quotes around marginal effects for two reasons. First, we remain a long ways from establishing causality at this point, and even where the paper ultimately makes the best progress (e.g., the state-border analysis) these techniques do not cover all outcomes. Thus, we use the term for convenience but under these caveats. Second, we are using localized variations of states around their long-term averages of taxation, corruption, and growth. This is of course necessary, as the long-term levels of states are different, and no one state can map out the whole distribution. Thus our approach requires the important identifying assumption that the within-state movements observed in one part of the distribution would hold true for other states were they in that range. ${ }^{7}$

Panel A of Table $2 \mathrm{~b}$ provides marginal effects for the baseline linear specification in Column 1 of Table 2a, while Panel B considers the estimation with squared tax terms in Column 8. In Panel B, we show statistical significance using the indicated line for visual ease - estimates

\footnotetext{
${ }^{7}$ Along these lines, it is important to clarify how the long-term positions of states with respect to taxes and corruption influence our estimates. When looking at the simple linear interaction of taxation and corruption, we identify off of local shifts in variables, not their rank order. Estimates with squared terms utilize more of the state-level distribution to map out the non-linear relationship, but the estimates are still using variation within states. Thus, we do not need to argue that the full state distribution is exogenous, but we do need to maintain our identifying assumption that the within-state movements observed in one part of the distribution would hold true for other states were they in that range.
} 
to the left and above the line are precisely measured at a $10 \%$ level. The marginal effects are most powerful in states with low taxation and corruption (the upper left of Panel B). They are not distinguishable from zero in states with high taxes and corruption (lower right). In low corruption states, the marginal effects of taxation are statistically different from zero at all tax levels. In settings with high corruption, the marginal effects are only strong when taxes are very low. These patterns conform to the basic trade-offs discussed in the introduction.

We find similar results when using a first-differenced format, with the coefficients for taxation, corruption and their interaction being $0.088(0.045)^{*},-0.005(0.010)$, and -0.034 $(0.013)^{* * *}$, respectively. The efficiency of the first-differenced format versus the levels specification turns on whether the error term is autoregressive. If autoregressive deviations are substantial, the first-differenced form is preferred; a unit root error is fully corrected. If there is no serial correlation, however, first-differencing introduces a moving-average error component. The residual correlation is modestly lower for the levels estimations at 0.072 , making it the preferred technique. Either way, the results are quite comparable and continue to show expansions in economic activity that are connected to taxation, corruption, and their interactions.

Table 3a next considers growth rates as dependent variables $Y_{s, t}$. We retain the state fixed effects, so that these estimates test whether growth accelerates or declines for a state based upon lagged corruption and tax revenues. This approach tests the even stronger forms of Propositions 1 and 2. We include period fixed effects and control for the lagged level of the state to capture convergence or mean reversion processes. We consider four log growth measures: growth in state GDP, growth in state GDP per worker, growth in state employments, and growth in state establishment counts. As noted earlier, our model most centrally focuses on the GDP-linked measures, but we seek the broader estimates of employment and establishments as well.

Overall growth elasticities are strongest for state GDP growth. State employment growth and growth in state GDP per worker both contribute to overall GDP growth, in roughly equal proportions. This decomposition is not exact because we allow the lagged state level to adjust across specifications to match the dependent variable. These results are robust to including the regional or initial tax quartile controls. Growth in establishments is weaker than growth in employments. These patterns suggest that favorable taxation and corruption environments encourage more firms, more workers per firm, and higher productivity per worker.

Tables $3 \mathrm{~b}$ and $3 \mathrm{c}$ provide the distributional patterns for growth in state GDP and GDP per worker. Growth robustly accelerates in the least corrupt states until at least the 75 th percentile of taxes. On the other hand, growth only accelerates with taxation at very low tax rates in the most corrupt states, and the point estimates suggest growth actually declines with higher tax rates in the most corrupt states. Marginal effects for employment and establishment growth are similar in shape but not precisely measured.

In addition to the precision of individual coefficients, these models have a good overall fit as measured through partial R-squared values. These are determined by regressing the outcomes and our three core right-hand side variables on panel fixed effects and predicting the residuals. For growth regressions, we also include the lagged terms with the fixed effects. The R-squared value of residuals for the outcome variable on the residuals for the core right-hand side variables quantify the predictive power of the estimation after the fixed effects are removed. The partial R-squared values in the levels framework are $7 \%-9 \%$, and they are $3 \%-4 \%$ in the growth panels. 
Table 4 tests a different econometric approach where we drop the state fixed effects and instead model growth covariates. While we design our five-year panels to capture the mediumterm impact of taxation and corruption, we noted earlier the importance of testing sensitivity of looking at deviations around state fixed effects. We focus on core traits that the urban economics literature identifies as important for US city growth since the 1970s. We connect to this literature for two reasons. First, US growth has been concentrated in cities over the past decades, and we can provide sharper controls by building up from cities to states. As an example, temperature and housing supply capacity vary across cities within a single state, and so we design our controls for growth traits as population-weighted averages over cities within each state. Second, entrepreneurship is known to be the key driver in this urban growth literature (e.g., Glaeser et al. 2010, 2015), and thus we can connect to a broader line of research in this project with this approach.

We model both constant and time-invariant traits. The city growth literature strongly emphasizes the importance of climate and human capital to explain recent growth. Accordingly, our simplest covariate model includes a control for January temperature, to reflect the large shifts in population towards warmer climates, and a time-varying measure of the log share of workers with a bachelors' education, taken from the Decennial Censuses, to model the rise of the skilled city. We also consider an extended covariate model that further includes four additional controls: housing prices, population density, Bartik-style growth projections for employment using the initial industry distribution interacted with national growth by industry, and the housing supply elasticity of cities measured by Saiz (2010) through geographic features of cities like coastlines, elevation and mountains, and so on.

The encouraging news in Table 4 is that this approach yields many similar results to our fixed effect estimations. Our key focal point has been the negative interaction between taxation and corruption, which is robustly confirmed with the alternative specification. The main effects for taxation are weaker than in Table 3a, but they remain precisely estimated for GDP per worker growth. Beyond these six factors, we considered other growth-related traits like the number of highway lanes in the state in 1970, July temperature levels, annual snowfall totals, and aggregate population levels. While these factors often have univariate correlations with city growth, they do not stand out in multivariate frameworks with the other factors developed. Most important, however, is that the additional factors do not further influence the core interaction between taxation and corruption that is our focus.

Table 5 next extends our basic specification to various components of employment growth in a second decomposition exercise. The LBD dataset allows us to identify establishment ages, and we quantify the extent to which employment growth is in younger or older establishments. Both groups have comparable interaction effects, while the main effect of taxation for older establishments is larger. The third column measures how taxes and corruption influence entry/exit by summing employment in entering or exiting establishments. This pattern is very close to the young establishment estimations in Column 1. We find comparable results on the entry and exit margins individually. For entry, we also find mostly uniform patterns across different initial employment sizes of establishments. The fourth column estimates how taxes and corruption influence the average employment size of continuing establishments in the state. While borderline in statistical significance, these latter effects are important contributors to our overall growth patterns as continuing establishments typically account for over $80 \%$ of employment. 
Looking across these four columns, the overall employment growth effects are not due to any single channel, but instead a consequence of growth on multiple margins. This parallels our earlier patterns of equal contributions to state GDP growth from both growth in worker counts and growth in GDP per worker. Marginal effects across the taxation-corruption distribution for these outcomes are positive and have the predicted shapes. The consequence of the weaker main effects for taxation, however, is that these marginal effects are mostly statistically insignificant. The more precise estimates are for the older or continuing firms given their more powerful main effects.

Throughout this paper, we take a very broad view of the term innovation to mean any entrepreneurial efforts that seek to enhance a firm's sales and performance. These can include classic R\&D type activities, but much of the state GDP and employment patterns that we are observing here are related instead to non-R\&D firms: opening or expanding a new restaurant concept, launching a temporary help agency or gardening service, designing new chemical products for local customers, and so on. All of these innovators face the disincentive effects of taxation and the positive enhancement from local public goods being better provisioned.

While this broader picture is important for this paper, it is interesting to look briefly at one innovative activity - patenting - where we can also examine different types of firms (e.g., Hall et al. 2001). We assign patents to states based upon the location of inventors. Columns 5 and 6 look at the patenting by assignee age similar to Columns 1 and 2. The patterns are quite comparable, with a slightly larger point estimate for older patenting firms and a very sharp interaction effect of taxation and corruption for young patenting assignees. This suggests that the development of new patenting firms is particularly sensitive to the interaction between taxation and corruption. This exercise also has the benefit of showing our patterns in an additional data source beyond state GDPs and our LBD data.

To conclude this state-level analysis, we run Granger-style reverse regressions where the left-hand side outcomes are the previous period values of log state GDP, log state employment, log state GDP growth, and log state employment growth. As emphasized above, this test of timing is an important starting point for establishing a causal relationship. Table 6 shows that the interaction term between taxation and corruption is weak and statistically insignificant in these regressions. This provides some baseline confidence, if incomplete, that the panel outcomes observed thus far do not solely reflect reverse causality.

\subsection{County-Level Results}

The state-level results provide a comprehensive view of the linkages between taxation, corruption, and growth. Despite using lagged values of corruption and taxation to predict future growth, natural worries persist around potential endogeneity (e.g., local politicians become more corrupt with diminished growth prospects) or omitted factors correlated with our explanatory variables. Our empirical setting unfortunately does not lend itself to instrumental variables. While prior work has identified ways of instrumenting for one region's taxation with its neighbors (e.g., Gordon and Lee 2006), our main interest is in the interaction of taxation and corruption in a panel setting. We would thus require time-varying instruments for taxation and corruption across a 20-year period, which presents insurmountable challenges (especially for exogenous changes in local corruption).

We can make progress, however, towards this identification using spatial variations across counties in the extent to which they are influenced by the taxation and corruption of other 
states. Some counties are in the middle of big states and thus are only weakly influenced by other states, if at all. Other counties are on the edges of states and therefore are substantially influenced by what happens in other states. The identification concept is that Alabama's and Georgia's taxation, provision of public goods, corruption, etc. impact counties in the northern Florida panhandle much more than counties surrounding Miami, several hundred miles from the border. Moreover, while lagged corruption and taxation for state variables are perhaps endogenous to that state, they can be treated as exogenous for counties in other states. Taxation and corruption in Alabama and Georgia are most directly determined by what happens in their own big cities and state capitals (e.g., Atlanta, Birmingham, and Montgomery), yet the effects can be felt throughout the states (e.g., quality of roads and schools) and thus impact the counties in northern Florida.

Holmes (1998) provides a seminal application of using border effects to discern the economic effects of state policies, and Rohlin et al. (2010) provide an excellent recent application to the link between taxes and entrepreneurship. Border effects papers like these two typically describe whether there is more or less activity in a narrow spatial range on one side of the border versus the other side that is consistent with a policy difference between the states. Our approach differs from this work in two key ways. First, the nature of our underlying mechanisms requires a larger spatial range than a strict border discontinuity: corruption and public goods well beyond the first ten miles on the opposite side of the border can matter deeply for counties at the edge of states. ${ }^{8}$ Second, we only look at panel variation in economic determinants and outcomes. Thus, permanent differences in economic activity around the border due to long-term policy choices or corruption levels - which are typically the focus of border studies like Holmes' (1998) findings regarding right-to-work laws - are controlled for by panel effects.

While this spatial analysis provides a path towards a more causal statement, the impact that this approach will have on some of our coefficient magnitudes is less clear. For example, greater taxation that is efficiently translated into public goods in neighboring states should have positive effects for a border county, similar to our base estimation (17). It might be tempting to argue as well that there are no disincentive effects, as the entrepreneur in the border county is not immediately subject to the other state's taxes, so that the taxation-growth connection would be unambiguously positive. This argument, however, misses two pieces. First, as a technical matter, businesses pay taxes in states in which they sell products even if the firm is not physically located there, so this border effect for local taxes is not as sharp for many types of firms. But more importantly, taxes in the neighboring states can have disincentive effects for entrepreneurs in those states, and the resulting reduced growth can weaken sales opportunities and entrepreneurial incentives for firms in the border counties. Thus, many of the trade-offs we identified earlier persist, but we now have a setting where policies and corruption are determined with less reference to the border counties themselves.

Operationally, we construct a spatial ring around each county using its geographic centroid. We identify all counties that are within 100 miles of the focal county within both home and neighboring states. We then use employment in these identified counties to determine the share

\footnotetext{
${ }^{8}$ Audretsch and Feldman (1996), Rosenthal and Strange (2001, 2004), Ellison et al. (2010), and Kerr and Kominers (2015) describe the spatial lengths through which technology, product and labor markets can impact firms. Recent empirical work also highlights that entrepreneurs disproportionately operate in their home regions (e.g., Figueiredo et al. 2002, Michelacci and Silva 2007), which limits the extent to which entrepreneurs would simply move to better opportunities.
} 
of economic activity in the 100-mile radius that comes from each identified state. Every county has at least some share from its home state; the average share is $68 \%$, and the home state share is $100 \%$ for many counties. But many counties are influenced by one or more states other than their home states. We then use these state shares within 100 miles to develop more localized measures of tax revenues, corruption, and their interactions by taking the employment-weighted average across states. $38 \%$ of counties are on at least one state border, and $26 \%$ of counties draw more than half of their effective influence from states other than their home states. These measures are specific to focal counties, and thus they vary across counties within states.

Table 7 a considers county employment growth as the dependent variable in a framework akin to Column 5 of Table 3a. We include county and time period fixed effects, and we continue to cluster standard errors by state. The results are quite similar to those in our baseline statelevel estimates, but the estimates are stronger and more precisely measured. Moreover, the relative importance of the interaction effect to the baseline taxation effect has increased. This pattern is also repeated in Column 1 of Table $7 \mathrm{~b}$ for county growth in establishments, where the gains from Table 3a are even stronger. The deterioration in taxation's impact for growth due to corruption is sharper with these more localized measures. (Unfortunately, we do not have data to replicate the state GDP effects at the county level.)

The next four columns in both tables split the sample of counties. Columns 2 and 3 separate counties by whether or not they are on a state border. Columns 4 and 5 separate counties by whether or not they have over $50 \%$ of the localized activity around them determined by other states (which is the basis for the county-specific measures of taxation and corruption). Elasticities in these periphery counties are very similar to those in the interiors of states. Across the two tables, the main effects for taxation are stronger in the periphery areas in three of the four pairings, and the interaction effects are stronger in all four decompositions for the periphery areas. The standard errors for the periphery areas tend to be larger, but that is a natural consequence of the reduced sample size for estimations. The last two columns show similar results if we narrow or widen the radius of the county-centered area to 50 miles or 200 miles, respectively. ${ }^{9}$

Looking across Tables $7 \mathrm{a}$ and $7 \mathrm{~b}$, the persistence of the interaction effects provides strong support for the idea that local corruption can deteriorate potential positive benefits of taxation for public goods and economic growth. While corruption and taxation choices will always have endogenous elements, the patterns we observe continue to hold when examining periphery counties where most of the surrounding taxation and corruption come from other states. This spatial robustness gives us additional confidence in our main growth results in Table 3a.

\subsection{Discussion}

Before turning to our quantification exercises, we pause to reflect on this section's empirical findings and the extent to which they align with our theoretical model. Our empirical evidence as whole provides reasonable evidence for the model's predictions; not perfect by any means, but hopefully allowing some confidence regarding the usefulness of our upcoming calibrated estimates. We see two places where the results are strong. The first is the core model prediction that corruption dampens or reverses a potential positive growth stimulus from taxation at low tax rates. We have been impressed by the degree to which the data align with this prediction as

\footnotetext{
${ }^{9}$ These patterns are quite similar when including squared taxation terms in periphery estimations. The squared terms are almost always statistically insignificant and small in economic size.
} 
the prediction is rather complex, involving interactions of two variables in a panel econometric setting. The result also holds in a variety of robustness checks and in state- and countylevel growth outcomes. A second place where we believe the results speak pretty well is in the direction of causation: that corruption and taxation can influence growth. We readily acknowledge that we remain far from a complete proof in this regard, but the accumulated evidence using Granger-style tests and state borders is encouraging. We hope future research can further push on this front.

There are other areas where the model receives less support. First, our evidence for the predicted inverted-U format of taxation for growth is modest. We almost always find a negative coefficient on the squared taxation term when it is included in estimations. It is statistically significant for growth of state GDP and in the levels approaches, while it is smaller and not different from zero for the other growth measures. While a limitation of our empirical results, we are comfortable with this outcome as the inverted-U shape is less critical than the negative interaction effect. Moreover, the root cause of this limited finding appears to be that the empirical variation across US states in taxation, corruption, and growth is limited to the lefthand-side of the inverted-U curve. The calibration in the next section will suggest this for the United States as a whole. That is, we do not have Zimbabwe-type corruption scenarios in our sample, and we do not have settings with $50 \%+$ tax rates. As the variation in the United States is more modest, it is natural that we mostly capture the concavity of the relationship to the left of the peak. This too is a natural vein for future work as consistent cross-country data become available.

Perhaps the largest gap between the theory and empirics is for the negative main effect of corruption. Most of our point estimates for corruption's impact are negative, consistent with the theory, but they are only really powerful in the growth regressions that lack state fixed effects. In other words, our empirical work finds it hard to really nail down this main prediction using the panel variation that we feel important for identification. We can identify a connection that corruption has to taxes, but overall the implications of corruption and efficiency have residual uncertainty to them. This is an important limitation to acknowledge given that the calibrations strongly emphasize the impact that improved government effectiveness can have on growth. Glaeser and Saks (2006), using data similar to those we use in this paper, also find overall evidence of a decline in state-level growth with higher rates of corruption, but their work too notes differences across outcome variables and specifications in the strength of this result, which we are also seeing evidence for. Given the empirical and data advantages of regional variation in the United States, we hope new measures beyond convictions of public officials emerge for further analysis. ${ }^{10}$

Finally, we have focused the empirical work in this paper on panel econometric approaches, whereas recent research finds important insights about related problems using applied-macro techniques like panel cointegration (Coe et al. 2009, Bronzini and Piselli 2009). Many of the series that we consider in this paper do not have unit roots (e.g., corruption measured through convictions of public officials relative to state size), and thus the core of this methodology does not connect well to our current work. We do believe, however, that it is important to bring

\footnotetext{
${ }^{10}$ Other settings appear to yield this result more easily - Prakash et al. (2014) find stronger direct support for corruption's implications on growth in India; Olken and Pande (2012) provide a broader review in the developing country context. While the micro and case study evidence tend to point towards a negative effect of corruption, the macro evidence is inconclusive (e.g., Mauro 1995, Svensson 2005). Paserman et al. (2008) show the degree of country openness moderates the impact of corruption.
} 
a variety of techniques to studying this complex problem, and we hope that future work can consider some of these parallel approaches.

\section{Generalized Model with Capital and Calibration}

In this section, we generalize the previous model by introducing capital. We then calibrate the model to estimate the growth consequences of adjustments in taxation and corruption levels.

\subsection{Introducing Capital into the Model}

Consider the previous economy with the following modifications. The household also owns a balanced portfolio of all the firms $A_{t}$ and the entire capital stock $K_{t}$ in the economy, which depreciates at the rate $\delta_{k}$, and the household chooses its level of investment in terms of units of the final good. The flow rate of capital is given by

$$
\dot{K}_{t}=-\delta_{K} K_{t}+H_{t}
$$

where $H_{t}$ is the household's capital investment. Therefore, the household's budget constraint is

$$
C_{t}+H_{t}+\dot{A}_{t}=w_{t} L_{t}+R_{t} K_{t}+r_{t} A_{t}+\beta T_{t}
$$

where $R_{t}$ is the rental rate of capital. The unique final consumption good $Y_{t}$ is produced using capital $K_{t}$ and continuum of intermediates $z$ (indexed by $i$ ) according to the CRS production function

$$
Y_{t}=K_{t}^{\xi} Z_{t}^{1-\xi}
$$

where $Z_{t}$ is the basket of intermediate varieties as before.

With these modifications, following similar steps as before that are shown in the appendix, the equilibrium growth rate is equal to

$$
g^{*}=\left[\frac{(1-\beta) \tau \Pi^{*}}{\delta_{\alpha}\left(1-s^{*}\right)(1-\tau) \phi}+\frac{\phi(1-\tau)(1-\beta) \tau}{\delta_{\alpha}}\left[\frac{\Pi^{*}}{1-s^{*}}\right]^{2}-\rho\right] \ln (1+\lambda),
$$

where

$$
\Pi^{*} \equiv \frac{(1-\xi) \lambda}{1+\lambda}-\frac{\left(1-s^{*}\right)}{2 \phi^{2}(1-\tau)^{2}}
$$

is the operating profits. Note that these expressions depend on the saving rate $s \equiv 1-C / Y$. The equilibrium saving rate can be expressed as

$$
s^{*}=\left(\frac{g^{*}+\delta_{K}}{g^{*}+\delta_{K}+\rho}\right) \xi \text {. }
$$

We take this generalized model to the data and calibrate it. In the calibrations below, we shall also look at the effects of taxation and corruption on aggregate welfare. Since welfare is affected not just by growth but also by initial consumption, the effect of taxation on welfare 
will also operate through its effect on the allocation of workers in the economy. More precisely, equilibrium welfare is equal to

$$
\begin{aligned}
U^{*} & =\int_{0}^{\infty} e^{-\rho t}\left(\ln C_{0} e^{g^{*} t}-L^{*}\right) d t \\
& =\frac{1}{\rho}\left[\ln C_{0}-L^{*}\right]+\frac{g^{*}}{\rho^{2}} .
\end{aligned}
$$

In our analysis, we will consider consumption equivalent measures of welfare. The following lemma will help us evaluate how changes in taxation affect welfare:

Lemma 2 Let $\chi$ be defined as the consumption equivalent change in welfare between two different policies $\tau$ and $\tau^{\prime}$ such that

$$
U\left(C_{0}^{*}(\tau), L^{*}(\tau), g^{*}(\tau)\right)=U\left(\chi C_{0}^{*}\left(\tau^{\prime}\right), L^{*}\left(\tau^{\prime}\right), g^{*}\left(\tau^{\prime}\right)\right) .
$$

Consumption equivalence $\chi$ is given by

$$
\chi=\frac{C_{0}\left(\tau^{\prime}\right)}{C_{0}(\tau)} \exp \left(L(\tau)-L\left(\tau^{\prime}\right)+\frac{g^{*}\left(\tau^{\prime}\right)-g^{*}(\tau)}{\rho}\right) .
$$

\subsection{Calibration}

This section calibrates our model to provide quantitative insights into the possible growth implications of adjustments in US taxation rates and corruption/efficiency levels. To do so, our model requires calibrating the following parameters: the discount rate $\rho$, the innovation step size $\lambda$, the corruption level $\beta$, the tax rate $\tau$, the infrastructure depreciation rate $\delta_{\alpha}$, the capital depreciation rate $\delta_{K}$, and the entry cost $\phi$.

We first set several parameters using benchmark values from the literature. We set the discount rate as $\rho=0.04$, which corresponds to the average 10-Year Treasury Constant Maturity Rate minus inflation over 1982-2007. We next fix the depreciation rates $\delta_{\alpha}=\delta_{K}$ at the benchmark $15 \%$ rate for equipment and machinery. We finally set the capital share of expenditure at 29.5\% $(\xi=0.295)$ following Aghion et al. (2013) and typical values from the business cycle literature.

We use the key moments predicted by our model to identify the remaining parameters. The first moment M1 is the employment share of entrants that is computed from the Census Bureau data over 1982-2005. The second moment M2 is the aggregate growth rate of the innovating sector in the US economy that is also calculated from Census Bureau data by Acemoglu et al. (2011). The third moment M3 is the average profitability of US firms before taxation, obtained from the Bureau of Economic Analysis for 1982-2007. The final moment M4 is the corporate tax revenue share of GDP over 1982-2007. Our target moments and their values are summarized as:

\begin{tabular}{ccl}
\hline Moment & Value & Description \\
\hline M1 & 0.058 & Entrant employment share \\
M2 & 0.022 & Growth rate \\
M3 & 0.091 & Average profitability before tax \\
M4 & 0.034 & Corporate tax revenue over GDP \\
\hline
\end{tabular}


We divide M4 by M3 to pin down the average tax rate $\tau$. Next, we use M2, M3 and M4 jointly to solve for $\lambda, \beta$ and $\phi$. The calibrated values are:

\begin{tabular}{ccl}
\hline Parameter & Value & Description \\
\hline$\lambda$ & 0.205 & Innovation step size \\
$\phi$ & 5.794 & Outsider's innovation technology \\
$\beta$ & 0.243 & Average corruption \\
$\tau$ & 0.374 & Average corporate tax rate \\
$\delta_{\alpha}$ & 0.150 & Infrastructure depreciation rate \\
$\xi$ & 0.295 & Capital share of expenditure \\
$\delta_{K}$ & 0.150 & Capital depreciation rate \\
\hline
\end{tabular}

We next report the equilibrium values of some of the endogenous variables. The first two rows provide shares of GDP, with labor income and capital income shares being $67.4 \%$ and $29.5 \%$, respectively. Our calibrated model predicts that corruption revenue amounts to a little less than $1 \%$ of GDP.

The next three rows provide the allocation of labor across functions. $86.9 \%$ of workers are involved in production activities, while about $9.3 \%$ are involved in innovation efforts as either incumbents or outsiders. This innovation employment share is quite reasonable given our broad definition of innovation efforts. To take manufacturing as an example, in 1997 there were 363 thousand establishments that employed 12.1 and 4.7 million production and non-production workers, respectively. A strict lower bound would be that there is one innovation worker per establishment (e.g., the business owner), which would imply an innovation worker share of $2 \%$. On the other hand, saying that all non-production workers are involved in innovation would result in a share of $28 \%$. Our calculation suggests that one in every three non-production workers is involved in innovation efforts. ${ }^{11,12}$

Finally, the calibration estimates that the innovation rate per product line is about $12 \%$ $(6.2 \%+5.8 \%)$. At this rate, an innovation occurs in a product line on average every eight years. The calibration suggests that the rate coming from incumbents is $7 \%(=6.2 / 5.8-1)$ more than the rate of successful outsiders.

\begin{tabular}{ccl}
\hline Variable & Value & Description \\
\hline$L w / Y$ & $67.40 \%$ & GDP share: Labor income \\
$s$ & $23.94 \%$ & GDP share: Investment \\
$\beta T / Y$ & $0.83 \%$ & GDP share: Corruption \\
$L_{P} / L$ & $86.88 \%$ & Labor share: Production workers \\
$\left(L_{I}+L_{E}\right) / L$ & $9.30 \%$ & Labor share: Innovation workers \\
$L_{G} / L$ & $3.82 \%$ & Labor share: Government workers \\
$x$ & $6.22 \%$ & Incumbent's innovation intensity \\
$\tilde{x}$ & $5.80 \%$ & Entry rate \\
\hline
\end{tabular}

We next consider the relationship between corruption, taxation, and growth. Figure 1 plots the equilibrium growth rate as a function of the corporate tax rate. As predicted by our

\footnotetext{
${ }^{11}$ As a second benchmark, US Census Bureau reports that $3 \%$ of the population (above 25 years of age) hold advanced degrees.

${ }^{12}$ The government share of the workforce is $4 \%$, which is low compared to the roughly $15 \%$ of US workers employed by state and local governments. This difference is mostly due to our one-for-one technology for infrastructure provision embodied in (6).
} 
analysis in the previous section, the relationship between taxation and growth is an inverted-U shaped pattern. The peak occurs at $\tau_{\max }=42.47 \%$, marked by the dashed line, which indicates that the empirical tax rate $(37 \%)$ is quite close to the growth maximizing level for the current level of corruption. Figure 2 plots the equilibrium growth rate as a function of the tax rate and the corruption rate $\beta$. For any given tax rate, higher corruption leads to a lower growth rate. According to the calibrated numbers and holding constant the tax rate at its current level, removing corruption completely $(\beta=0)$ from its current level of $\beta=0.243$ improves the growth rate to $3.23 \%$. This is a substantial increase of $22 \%$ in consumption equivalent terms.

The intuition behind the inverted-U shaped pattern comes from the two opposing effects of taxation. Taxation allows the government to provide better infrastructure, which in turn makes firms more productive and enhances growth. On the other hand, higher taxation lowers monopoly rents, and this negative effect becomes the dominant factor beyond a certain tax rate. Higher corruption dampens the positive effect of taxes by simply taking away the available resources that could have been utilized for growth enhancing infrastructure.

Turning to welfare, we use expression (19). It is more informative to discuss the consumption equivalent variation $(\chi)$ after tax changes, and Figure 3 plots $\chi$ as a function of the tax rate $\tau$. Note that by construction, $\chi=1$ at the empirical tax rate $\tau=37 \%$. The plot indicates the percentage change in initial consumption that would make the household indifferent between the empirical tax rate and the counterfactual tax rate. The main difference between welfare and growth is the labor supply component in the former, which is simply equal to the disutility of work. However, our quantitative analysis shows that the effect of taxation on welfare is driven mostly through its impact on growth. Hence, the growth and welfare maximizing tax rates are very close to each other. The welfare maximizing tax rate is computed as $42.3 \%$, which is 5.3 percentage points higher than the current calibrated tax rate $\tau=37 \%$. We estimate that a modest $1.1 \%$ welfare gain would accrue from setting the optimal tax rate while holding fixed current corruption levels.

More interestingly, Figure 4 plots the consumption equivalent gain from changing the corruption level. The value is one at $\beta=0.243$ by construction. At the extreme, removing the corruption completely $(\beta=0)$ results in a $22 \%$ consumption equivalent welfare gain, and reducing corruption by very modest amounts provides the same welfare gain as optimizing taxation for the current level of corruption. Taken a step further, eliminating corruption would raise the optimal tax to $42.5 \%$, which would further boost growth to $3.3 \%$ and welfare by $24 \%$ in consumption equivalent terms.

Turning to extensions, the impact of taxation and corruption on the equilibrium firm size distribution (FSD) is ambiguous due to two opposing effects. Better environments enhance the productivity of incumbent firms, leading to growth in average firm size through additional product lines, but higher entry rates and incumbent displacement are also encouraged. Figures 5 plots the FSD against tax rates, whereas Figure 6 plots average firm size against tax rates. Initially, taxation increases reduce average firm size. As the tax rate increases, after a certain point, the tail of the distributions starts getting fatter. Figure 6 shows that the average firm size initially decreases and then starts rising for $\tau$ beyond around $23 \%$. This is mainly driven by the competitive pressure imposed on incumbents from new entrants.

The tax rate that maximizes economic growth also maximizes innovation for a given corruption level. We earlier noted that incumbents' innovation rate per product line in this calibration is higher than the success rate of outsiders for acquiring their first product line. Figure 7 plots 
the ratio of the entrants' innovation intensity to total innovation intensity $\tilde{x} /(x+\tilde{x})$ by tax rate for the calibrated corruption level. The relative innovation rate by the entrants features an inverted-U shaped pattern. Starting from zero, initial taxation benefits entrants more than incumbents. As a result, incumbent firms face tighter competition and cannot grow in size as much. This competitive pressure initially increases with higher tax rates due to more innovation by entrants. However, when the tax rate is already sufficiently large, the negative effect of taxation starts to dominate and discourages entrants from investing in innovation due to lower returns. This weakens the competitive pressure on incumbents, they expand in size, and they thereby generate a greater share of the economy's innovations. As the incumbents' innovation rate per product line is higher than the success rate of outsiders for acquiring their first product line, the tax rate that maximizes the entrant share is lower than the tax rate that maximizes growth. Removing corruption increases the entrant share at all tax rates, while further pushing down the tax rate that maximizes the entrant share. ${ }^{13}$

To conclude, our calibrated model estimates substantial growth rate reductions and welfare losses are present in the US economy due to corruption and non-optimal tax rates. The gains from optimizing the tax rate are fairly modest, in the range of $1 \%$. The potential gains from improving government efficiency are estimated to be much larger and over 20\%. Most of the welfare losses come from poor use of government funds, not from the sub-optimal tax.

\section{Conclusion}

In this paper we have analyzed the effect of taxation and corruption on growth, innovation, and entry. First, we have built an endogenous growth model with quality-improving innovations that lead to the new product lines, and then calibrated this model to assess the welfare effects of the interaction between taxation and corruption. Then, using cross-state and then crosscounty panel data from the Longitudinal Business Database (LBD) of the US Census Bureau, we have obtained evidence that is consistent with the theoretical prediction that the effect of taxation on growth and innovation should be increasing and concave, and that higher local corruption should weaken the positive effect of taxation on growth, innovation, and entry. Evidence also suggests this effect operates through entrepreneurial channels consistent with the model's structure.

This paper is a very first step in a broader research agenda on how to factor in growth and innovation considerations in optimal tax design. In particular, there are large debates in the US Congress and among European countries on how progressive the income tax should be and on the desirable corporate tax rate. However, analyses of these issues often do not feature innovation and growth as leading criteria in the design of a desirable tax system. We believe it very important to begin linking the growth and revenue sides of the public ledger to the spending side and the overall effectiveness on how public funds are spent. This paper makes several forays into theoretical and empirical dimensions, and we believe we are just scratching the surface of what could be exciting and important research aimed at better linking public finance conditions to entrepreneurship, innovation, and growth.

\footnotetext{
${ }^{13}$ This model does not allow entrants and incumbents to engage in different types of innovation or to have different step sizes to their innovations (e.g., Akcigit and Kerr 2010). Building these differences into the model would have a larger impact on this part of the calibration and the comparison of entrants and incumbents than on other parts of the model.
} 


\section{References}

[1] Acemoglu, D (2009), Introduction to Modern Economic Growth, Princeton, NJ: Princeton University Press.

[2] Acemoglu, D, Akcigit, U, Bloom, N, and W. Kerr (2011), "Innovation, Reallocation, and Growth", Working Paper.

[3] Acs, Z, and C. Armington (2006), Entrepreneurship, Geography and American Economic Growth, New York, NY: Cambridge University Press.

[4] Aghion, P, Akcigit, U, and J. Fernandez-Villaverde (2013), "Optimal Capital Versus Labor Taxation with Innovation-Led Growth", Working Paper.

[5] Aghion, P, and P. Bolton (1997), "A Trickle-Down Theory of Growth and Development", Review of Economic Studies, 64, 151-172

[6] Aghion, P, Fally, T, and S. Scarpetta (2007), "Credit Constraints as a Barrier to the Entry and Post-Entry Growth of Firms: Theory and Evidence", Economic Policy, 22: 52, 731-779.

[7] Aghion, P, and P. Howitt (1992), "A Model of Growth Through Creative Destruction", Econometrica, 110, 323-351.

[8] Aghion, P, and P. Howitt (2009), The Economics of Growth, MIT Press.

[9] Akcigit, U, and W. Kerr (2010), "Growth through Heterogeneous Innovations", NBER Working Paper 16443.

[10] Aschauer, D (1989), "Is Public Expenditure Productive?" Journal of Monetary Economics, 23, 177-200.

[11] Audretsch, D, and M. Feldman (1996), "R\&D Spillovers and the Geography of Innovation and Production", American Economic Review, 86, 630-640.

[12] Banerjee, A, and A. Newman (1993), "Occupational Choice and the Process of Development", Journal of Political Economy, 101:2, 274-298.

[13] Barro, R (1990), "Government Spending in a Simple Model of Endogenous Growth", Journal of Political Economy, 98, 103-125.

[14] Barro, R (1991), "Economic Growth in a Cross Section of Countries", Quarterly Journal of Economics, 106, 407-443.

[15] Barro, R, and X. Sala-i-Martin (1995), Economic Growth, Cambridge: MIT Press.

[16] Baumol, W (1990), "Entrepreneurship: Productive, Unproductive, and Destructive", Journal of Political Economy, 98, 893-921.

[17] Benabou, R (1996), "Inequality and Growth", in B. Bernanke and J. Rotemberg, eds, NBER Macroeconomics Annual, 11, MIT Press.

[18] Bronzini, R, and P. Piselli (2009), "Determinants of Long-Run Regional Productivity with Geographical Spillovers: The Role of R\&D, Human Capital and Public Infrastructure", Regional Science and Urban Economics, 39:2, 187-199.

[19] Calderon, C, and L. Serven (2004), "The Effects of Infrastructure Development on Growth and Income Distribution", World Bank Policy Research Working Paper 3400. 
[20] Chakraborty, S, and E. Dabla-Norris (2011), "The Quality of Public Investment", The B.E. Journal of Macroeconomics, 11:1, 1-29.

[21] Coe, D, Helpman, E, and A. Hoffmaister (2009), "International R\&D Spillovers and Institutions", European Economic Review, 53:7, 723-741.

[22] Del Monte, A, and E. Papagni (2001), "Public Expenditure, Corruption, and Economic Growth: The Case of Italy", European Journal of Political Economy, 17:1, 1-16.

[23] Del Monte, A, and E. Papagni (2007), "The Determinants of Corruption in Italy: Regional Panel Data Analysis", European Journal of Political Economy, 23:2, 379-396.

[24] Djankov, S, Ganser, T, McLiesh, C, Ramalho, R, and A. Shleifer (2010), "The Effect of Corporate Taxes on Investment and Entrepreneurship", American Economic Journal: Macroeconomics, 2, 31-64.

[25] Duranton, G, and D. Puga (2004), "Micro-Foundations of Urban Agglomeration Economies", in J.V. Henderson and J.-F. Thisse, eds, Handbook of Regional and Urban Economics, Volume 4, Amsterdam: North-Holland, 2063-2117.

[26] Ellison, G, Glaeser, E, and W. Kerr (2010), "What Causes Industry Agglomeration? Evidence From Coagglomeration Patterns", American Economic Review, 100, 1195-1213.

[27] Figueiredo, O, Guimaraes, P, and D. Woodward (2002), "Home-Field Advantage: Location Decisions of Portuguese Entrepreneurs", Journal of Urban Economics 52:2, 341-361.

[28] Fiorino, N, Galli, E, and I. Petrarca (2012), "Corruption and Growth: Evidence from the Italian Regions", European Journal of Government and Economics, 1:2.

[29] Fisman, R, and R. Gatti (2002), "Decentralization and Corruption: Evidence Across Countries", Journal of Public Economics, 83, 325-345.

[30] Galor, O, and J. Zeira (1993), "Income Distribution and Macroeconomics", Review of Economic Studies, 60, 35-52.

[31] Gentry, W, and G. Hubbard (2005), "Success Taxes, Entrepreneurial Entry and Innovation", in A. Jaffe, J. Lerner and S. Stern, eds, Innovation Policy and the Economy, Volume 5, Cambridge: MIT Press, 87-108.

[32] Glaeser, E (2008), Cities, Agglomeration and Spatial Equilibrium, Oxford: Oxford University Press.

[33] Glaeser, E, Kerr, S, and W. Kerr (2015), "Entrepreneurship, Mines, and Urban Growth", Review of Economics and Statistics, 92:7, 498-520.

[34] Glaeser, E, Kerr, W, and G. Ponzetto (2010), "Clusters of Entrepreneurship", Journal of Urban Economics, 67:1, 150-168.

[35] Glaeser, E, and R. Saks (2006), "Corruption in America", Journal of Public Economics 90:6-7, 1053-1072.

[36] Gordon, R, and Y. Lee (2007), "Interest Rates, Taxes and Corporate Financial Policies", National Tax Journal, 60:1, 65-84.

[37] Hall, B, Jaffe, A, and M. Trajtenberg (2001), "The NBER Patent Citation Data File: Lessons, Insights and Methodological Tools", NBER Working Paper 8498.

[38] Haltiwanger, J, Jarmin, R, and J. Miranda (2013), "Who Creates Jobs? Small vs. Large vs. Young", Review of Economics and Statistics, 95:2, 347-61 
[39] Hassett, K, and A. Mathur (2006), "Taxes and Wages", American Enterprise Institute Working Paper 128.

[40] Hauner, D, and A. Kyobe (2010), "Determinants of Government Efficiency", World Development, 38:11, 1527-42.

[41] Helms, L (1985), "The Effect of State and Local Taxes on Economic Growth, A Time Series-Cross Section Approach", Review of Economics and Statistics, 67, 574-582.

[42] Holmes, T (1998), "The Effects of State Policies on the Location of Manufacturing: Evidence from State Borders", Journal of Political Economy, 106, 667-705.

[43] Hulten, C (1996), "Infrastructure Capital and Economic Growth: How Well You Use It May Be More Important than How Much You Have", NBER Working Paper 5847.

[44] Jarmin, R, and J. Miranda (2002), "The Longitudinal Business Database", CES Working Paper.

[45] Kerr, W, and S. Kominers (2015), "Agglomeration Forces and Cluster Shapes", Review of Economics and Statistics, 97:4, 877-899.

[46] Klette, T-J, and S. Kortum (2004), "Innovating Firms and Aggregate Innovation", Journal of Political Economy, 112:5, 986-1018.

[47] Marshall, A (1920), Principles of Economics, London, UK: MacMillan and Co.

[48] Mauro, P (1995), "Corruption and Growth", Quarterly Journal of Economics, 110:3, 681712 .

[49] Mauro, P (1998), "Corruption and the Composition of Government Expenditure", Journal of Public Economics, 69:2, 263-279.

[50] Michelacci, C, and O. Silva (2007), "Why So Many Local Entrepreneurs?", Review of Economics and Statistics, 89:4, 615-633.

[51] Mofidi, A, and J. A. Stone (1990), "Do State and Local Taxes Affect Economic Growth?", Review of Economics and Statistics, 72:4, 686-691.

[52] Murphy, K, Shleifer, A, and R. Vishny (1991), "The Allocation of Talent: Implications for Growth", Quarterly Journal of Economics, 106, 503-530.

[53] Nanda, R (2011), "Entrepreneurship and the Discipline of External Finance," HBS Working Paper 11-098.

[54] Olken, B, and R. Pande (2012), "Corruption in Developing Countries", Annual Review of Economics, 4, 479-505.

[55] Paserman, D, Neeman, Z, and A. Simhon (2008), "Corruption and Openness", Berkeley Electronic Journal for Economic Analysis and Policy, 8:1, Article 50.

[56] Petrescu, I (2009), "Income Taxation and Self-Employment: The Impact of Progressivity in Countries with Tax Evasion", Working Paper, Harvard University.

[57] Prakash, N, M Rockmore, and Y. Uppal (2014), "Do Criminally Accused Politicians Affect Economic Outcomes? Evidence from India", Working Paper.

[58] Rohlin, S, Rosenthal, S, and A. Ross (2010), "State Tax Effects and Entrepreneurship: Estimates from a Border Model With Agglomeration Economies", Working Paper, Syracuse University. 
[59] Romer, P (1986), "Increasing Returns and Long-Run Growth", Journal of Political Economy, 94:5, 1002-1037.

[60] Romer, P (1990), "Endogenous Technological Change", Journal of Political Economy, 98:5, S71-S102.

[61] Romp, W, and J. de Haan (2007), "Public Capital and Economic Growth: A Critical Survey", Perspektiven der Wirtschaftspolitik, 8:1, 6-52.

[62] Rosenthal, S, and W. Strange (2001), "The Determinants of Agglomeration", Journal of Urban Economics, 50, 191-229.

[63] Rosenthal, S, and W. Strange (2004), "Evidence on the Nature and Sources of Agglomeration Economies", in J.V. Henderson and J.-F. Thisse, eds, Handbook of Regional and Urban Economics, Volume 4, Amsterdam: North-Holland, 2119-2171.

[64] Saiz, A (2010), "The Geographical Determinants of Housing Supply", Quarterly Journal of Economics, 125:3, 1253-1296.

[65] Singhal, M (2008), "Special Interest Groups and the Allocation of Public Funds", Journal of Public Economics, 92, 548-564.

[66] Straub, S (2008), "Infrastructure and Growth in Developing Countries: Recent Advances and Research Challenges", World Bank Policy Research Working Paper 4460.

[67] Straub, S (2011), "Infrastructure and Development: A Critical Appraisal of the Macro Level Literature", Journal of Development Studies, 47:5, 683-708.

[68] Svensson, J (2005), "Eight Questions about Corruption", The Journal of Economic Perspectives, 19:3, 19-42.

[69] Tanzi, V, and H. Davoodi (2000), "Corruption, Growth, and Public Finances", IMF Working Paper 00/182.

[70] Wilson, D (2009), "Beggar Thy Neighbor? The In-State, Out-of-State, and Aggregate Effects of R\&D Tax Credits", Review of Economics and Statistics, 91:2, 431-436. 


\section{Theoretical Appendix}

Proof of Lemma 1. We simply verify the conjecture $V(n)=v^{*} n Y_{t}$ :

$$
\begin{gathered}
r^{*} v n Y_{t}=\max _{x}\left\{[1-\tau] n\left[\pi^{*} Y_{t}-\frac{x^{2}}{2 \alpha^{2}} w_{t}\right]+x n v Y_{t}-\mu^{*} n v Y_{t}\right\} . \\
r^{*} v n=\max _{x}\left\{[1-\tau] n\left[\pi^{*}-\frac{x^{2}}{2 \alpha^{2}}\right]+x n v-\mu^{*} n v\right\} .
\end{gathered}
$$

As a result, the optimal choice is

$$
x=\frac{v \alpha^{2}}{1-\tau} .
$$

Substituting this value back into the value function we get

$$
\frac{v^{2} \alpha^{2}}{2[1-\tau]}-v\left[r^{*}+\mu^{*}\right]+[1-\tau] \pi^{*}=0
$$

Derivation of Growth Rate. From (2) and the optimal quantity of intermediate good $j$,

$$
\ln Y_{t}=\ln Q_{t}-\ln (1+\lambda),
$$

where $\ln Q_{t} \equiv \int_{0}^{1} \ln q_{t}(i) d i$ is defined as the quality index at time $t$. Therefore,

$$
g=\frac{\dot{Y}}{Y}=\frac{\dot{Q}}{Q}
$$

Next consider the change in the quality index after a small time interval $\Delta t$,

$$
\ln Q_{t+\Delta t} \equiv \int_{0}^{1}\left[\mu^{*} \Delta t \ln (1+\lambda) q(i)+\left(1-\mu^{*} \Delta t\right) \ln q(i)\right] d i
$$

Some simple algebra leads to $\ln Q_{t+\Delta t}-\ln Q_{t}=\mu^{*} \Delta t \ln (1+\lambda)$. Dividing both sides by $\Delta t$ and taking the limit as $\Delta t \rightarrow 0$ delivers

$$
g^{*}=\frac{\dot{Q}}{Q}=\mu^{*} \ln (1+\lambda) .
$$

Proof of Proposition 1. Using (13) - (16), the growth rate is

$$
g^{*}(\tau)=\frac{[1-\beta][1-\tau] \tau \phi}{\delta_{\alpha}}\left[\frac{\lambda^{2}}{[1+\lambda]^{2}}-\frac{1}{4 \phi^{4}[1-\tau]^{4}}\right] \ln (1+\lambda)-\rho \ln (1+\lambda) .
$$

Then the derivative with respect to $\tau$ is

$$
\frac{\partial g^{*}(\tau)}{\partial \tau}=\underbrace{\chi(1-2 \tau)\left[\frac{\lambda^{2}}{(1+\lambda)^{2}}-\frac{1}{4 \phi^{4}[1-\tau]^{4}}\right]}_{\Phi(\tau)}-\frac{\chi \tau}{\phi^{4}[1-\tau]^{4}},
$$


where $\chi \equiv \frac{[1-\beta] \ln (1+\lambda) \phi}{\delta_{\alpha}} . \Phi(\tau)$ is monotonically decreasing in $\tau$ and $\Phi(0)>0$ by Assumption 1. Therefore $\left.\frac{\partial g^{*}(\tau)}{\partial \tau}\right|_{\tau=0}>0$ and $\left.\frac{\partial g^{*}(\tau)}{\partial \tau}\right|_{\tau=\tau_{g}}=0$ when

$$
\left[1-\tau_{g}\right]^{2} \sqrt{\frac{1-2 \tau_{g}}{1+2 \tau_{g}}}=\frac{1+\lambda}{2 \lambda \phi^{2}} .
$$

Proof of Proposition 2. The entry rate is

$$
\tilde{x}^{*}=[1-\tau] \tau \frac{[1-\beta] \phi}{\delta}\left[\pi^{*}-\frac{1}{2 \phi^{2}[1-\tau]^{2}}\right]^{2}-\rho .
$$

The derivative with respect to the tax rate is

$$
\begin{aligned}
\frac{\partial \tilde{x}^{*}}{\partial \tau} & =[1-2 \tau] \kappa\left[\pi^{*}-\frac{1}{2 \phi^{2}[1-\tau]^{2}}\right]^{2}-\frac{\tau 2 \kappa}{\phi^{2}[1-\tau]^{2}}\left[\pi^{*}-\frac{1}{2[1-\tau]^{2} \phi^{2}}\right] \\
& =\kappa[1+2 \tau] \underbrace{\left[\frac{[1-2 \tau]}{[1+2 \tau]} \pi^{*}-\frac{1}{2[1-\tau]^{2} \phi^{2}}\right]}_{\Psi(\tau)} \underbrace{\left[\pi^{*}-\frac{1}{2[1-\tau]^{2} \phi^{2}}\right]}_{\Pi(\tau)},
\end{aligned}
$$

where $\kappa \equiv[1-\beta] \phi / \delta$. Note that $\Pi(\tau)>0$ for all $\tau \in[0, \bar{\tau}]$. Moreover $\Psi(\tau)$ is monotone decreasing in $\tau, \Psi(\tau)<\Pi(\tau)$ and $\Psi(0)>0$. The peak of the inverted-U happens when $\Psi\left(\tau_{\tilde{x}}\right)=0$ such that

$$
\frac{\left[1-2 \tau_{\tilde{x}}\right]\left[1-\tau_{\tilde{x}}\right]^{2}}{\left[1+2 \tau_{\tilde{x}}\right]}=\frac{1}{2 \pi^{*} \phi^{2}} .
$$

Then $\frac{\partial \tilde{x}^{*}}{\partial \tau}>0$ if and only if $\tau<\tau_{\tilde{x}}$.

Proof of Lemma 2. Define consumption equivalence as

$$
U\left(C_{0}^{*}(\tau), L^{*}(\tau), g^{*}(\tau)\right)=U\left(\chi C_{0}^{*}\left(\tau^{\prime}\right), L^{*}\left(\tau^{\prime}\right), g^{*}\left(\tau^{\prime}\right)\right) .
$$

From (19) this implies

$$
\frac{\ln C_{0}\left(\tau^{\prime}\right)-L^{*}\left(\tau^{\prime}\right)}{\rho}+\frac{g^{*}\left(\tau^{\prime}\right)}{\rho^{2}}=\frac{\ln \chi C_{0}(\tau)-L^{*}(\tau)}{\rho}+\frac{g^{*}(\tau)}{\rho^{2}},
$$

which delivers the desired result

$$
\chi=\frac{C_{0}\left(\tau^{\prime}\right)}{C_{0}(\tau)} \exp \left(L^{*}(\tau)-L^{*}\left(\tau^{\prime}\right)+\frac{g^{*}\left(\tau^{\prime}\right)-g^{*}(\tau)}{\rho}\right) .
$$

Derivation of the Equilibrium with Capital. Household maximizes discounted sum of future utilities subject to the budget constraint

$$
C_{t}+H_{t}+\dot{A}=R_{t} K_{t}+w_{t} L_{t}+\beta T_{t}+r A,
$$


where $H$ denotes the capital investment. This maximization delivers

$$
\begin{aligned}
& w^{*}=C \\
& R^{*}=\rho+\delta_{K}+g^{*} .
\end{aligned}
$$

The interest rate is $r^{*}=R^{*}-\delta_{K}=\rho+g^{*}$.

Next, we solve the monopolist's problem. Since the final goods production function is CRS Cobb-Douglas, and since factors are paid their marginal product, Euler's theorem implies that expenditure on intermediates is $(1-\xi) Y_{t}$ (i.e. expenditure share of $Z_{t}$ is $1-\xi$ ). Furthermore, logarithmic aggregation of intermediates implies that expenditure on each variety is the same. Therefore, demand for variety $i$ is given by:

$$
z_{t}(i)=\frac{(1-\xi) Y_{t}}{p_{t}(i)}
$$

Bertrand limit pricing in each product line $i$ implies that the current innovator firm prices at marginal cost of previous innovator, and therefore

$$
p_{t}(i)-M C_{t}(i)=\frac{\lambda w_{t}}{q_{t}(i)} .
$$

So monopolist profits are:

$$
\pi Y_{t}=\frac{(1-\xi) \lambda}{1+\lambda} Y_{t}=\left(\frac{1-\xi}{1-s}\right)\left(\frac{\lambda}{1+\lambda}\right) w^{*}
$$

where $C_{t}=(1-s) Y_{t}$. Next, we move onto the incumbent's innovation problem; the incumbent's value function of operating $n$ product lines is

$$
r V_{t}^{*}(n)-\dot{V}_{t}(n)=\max _{x}\{\underbrace{(1-\tau) n\left[\pi^{*} Y_{t}-\frac{w^{*}}{2}\left(\frac{x}{\alpha_{t}}\right)^{2}\right]}_{\begin{array}{c}
\text { instantaneous return } \\
+\underbrace{\mu^{*} n\left[V_{t}(n-1)\right.}_{\text {lose product line }}-V_{t}(n)]
\end{array}}+\underbrace{x n\left[V_{t}(n+1)-V_{t}(n)\right]}_{\text {gain product line }}\}
$$

where $\mu^{*}$ is the aggregate innovation rate in the economy. Conjecture $V^{*}(n)=v^{*} n Y_{t}$ :

$$
x^{*}=\frac{\alpha^{2} v^{*}}{(1-s)(1-\tau)} .
$$

Examining the entrant's problem, free entry means $V^{\text {out }}=0$. Also, $\mathbb{E} v=v^{*}$; therefore

$$
v^{*}=\frac{w_{t}}{\phi \alpha Y_{t}^{*}}=\frac{(1-s)}{\phi \alpha^{*}}
$$

and

$$
x^{*}=\frac{\alpha^{*}}{\phi(1-\tau)} .
$$


Along the BGP, the level of infrastructure is constant, which implies that

$$
F^{*}=\delta_{\alpha} \alpha^{*}
$$

Operating profits $\Pi^{*}$ are

$$
\Pi^{*} \equiv \pi^{*}-\frac{x^{2}(1-s)}{2\left(\alpha^{*}\right)^{2}}=\pi-\frac{(1-s)}{2 \phi^{2}(1-\tau)^{2}} .
$$

Government's balanced budget implies

$$
F^{*}=\frac{(1-\beta) \tau \Pi^{*}}{(1-s)} .
$$

So, equilibrium level of infrastructure is

$$
\alpha^{*}=\frac{(1-\beta) \tau \Pi^{*}}{\delta_{\alpha}(1-s)} .
$$

Solving for the entrants innovation flow rate,

$$
\tilde{x}^{*}=\frac{\phi(1-\tau) \alpha^{*} \Pi^{*}}{(1-s)}-\rho,
$$

and the aggregate innovation rate is

$$
\mu^{*}=\frac{\alpha^{*}}{(1-\tau) \phi}+\frac{\phi(1-\tau) \alpha^{*} \Pi^{*}}{(1-s)}-\rho .
$$

On the BGP, labor supply $L^{*}$ remains constant over time. Productivity growth (growth in $Q(t))$ will be determined by the aggregate destruction rate $\mu^{*}$ :

$$
g^{*}=\mu^{*} \log (1+\lambda)
$$

The next step is to derive the consumption share of output $1-s$. Capital stock has to grow at the same rate as productivity and output. Assume investment $H(t)$ is proportional to $K(t)$ (i.e. $H(t) / K(t)=\zeta$ ). Then, from the law of motion for capital,

$$
g^{*}=\zeta-\delta_{K}
$$

So, investment $H(t)=\left(g^{*}+\delta_{K}\right) K(t)$. Applying the Euler theorem to the final goods production gives $R^{*} K(t) / Y(t)=\xi$, which implies that

$$
H(t)=\frac{\left(g^{*}+\delta_{K}\right)}{R^{*}} \xi Y(t),
$$

and from the resource constraint, $H(t) / Y(t)=s$, which solves implicitly for the investment share of consumer expenditure

$$
s=\left(\frac{g^{*}+\delta_{K}}{g^{*}+\delta_{K}+\rho}\right) \xi
$$


Figure 1: Growth as a function of the tax rate

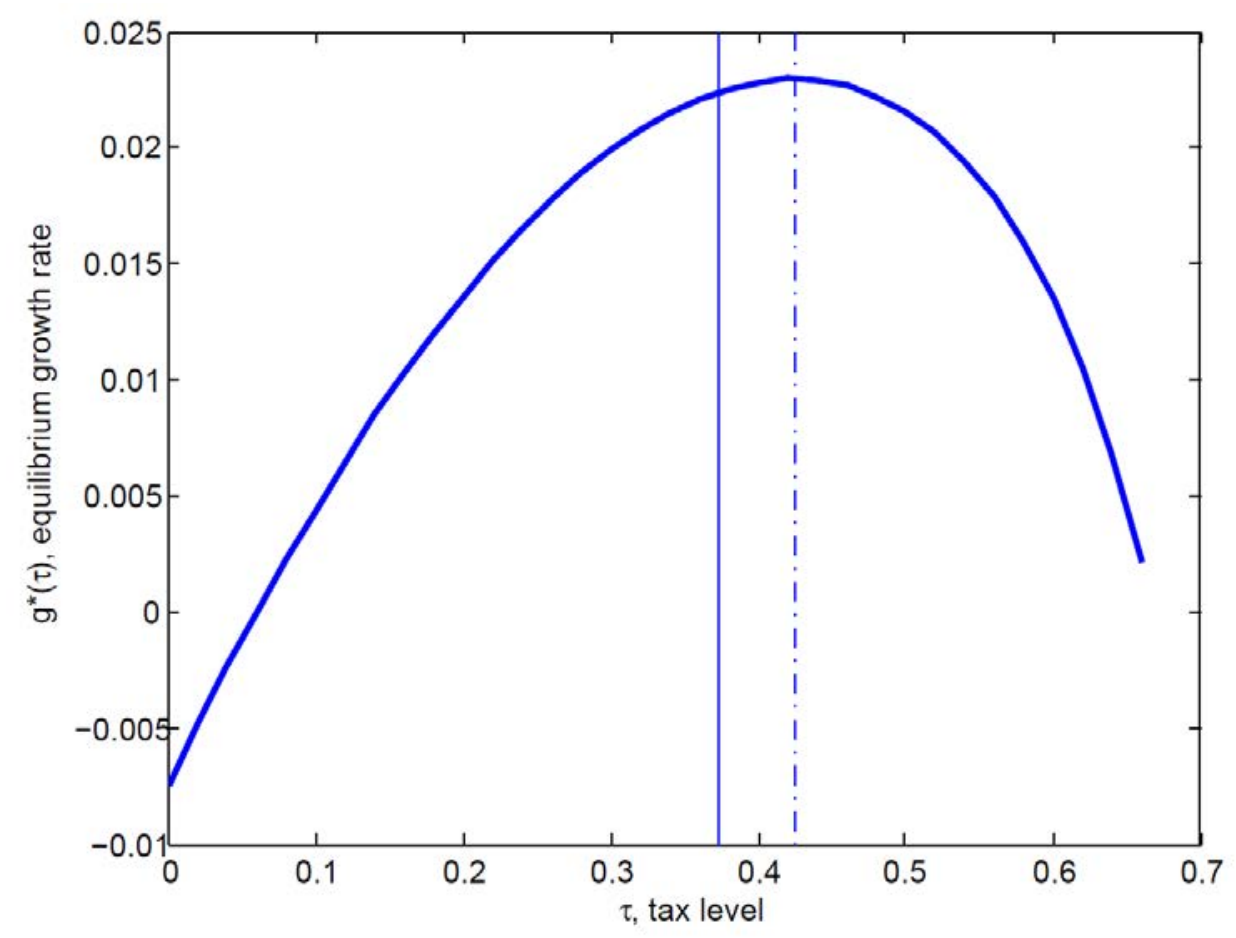

Figure 2: Growth as a function of the tax rate and corruption rate

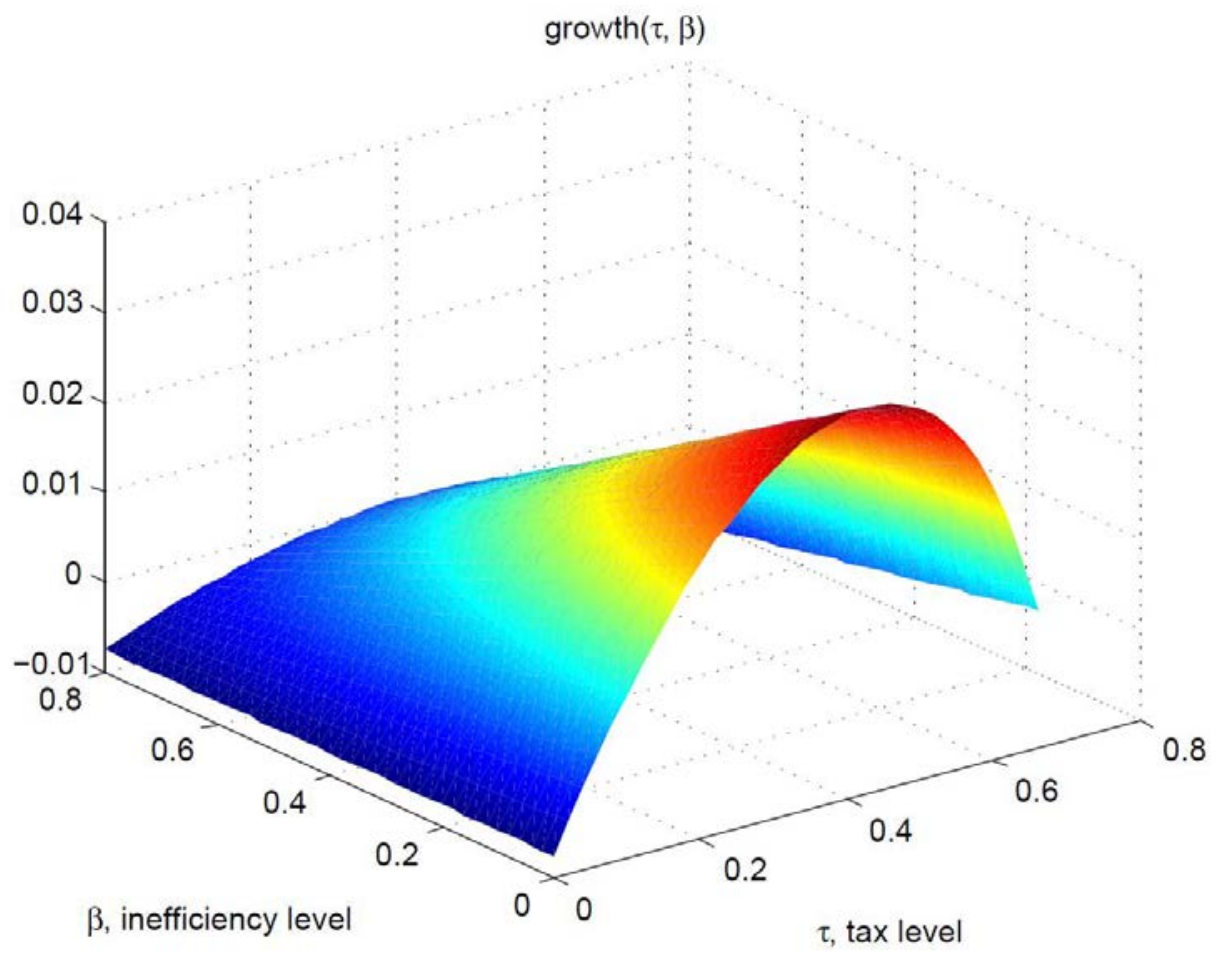


Figure 3: Consumption equivalence as a function of the tax rate

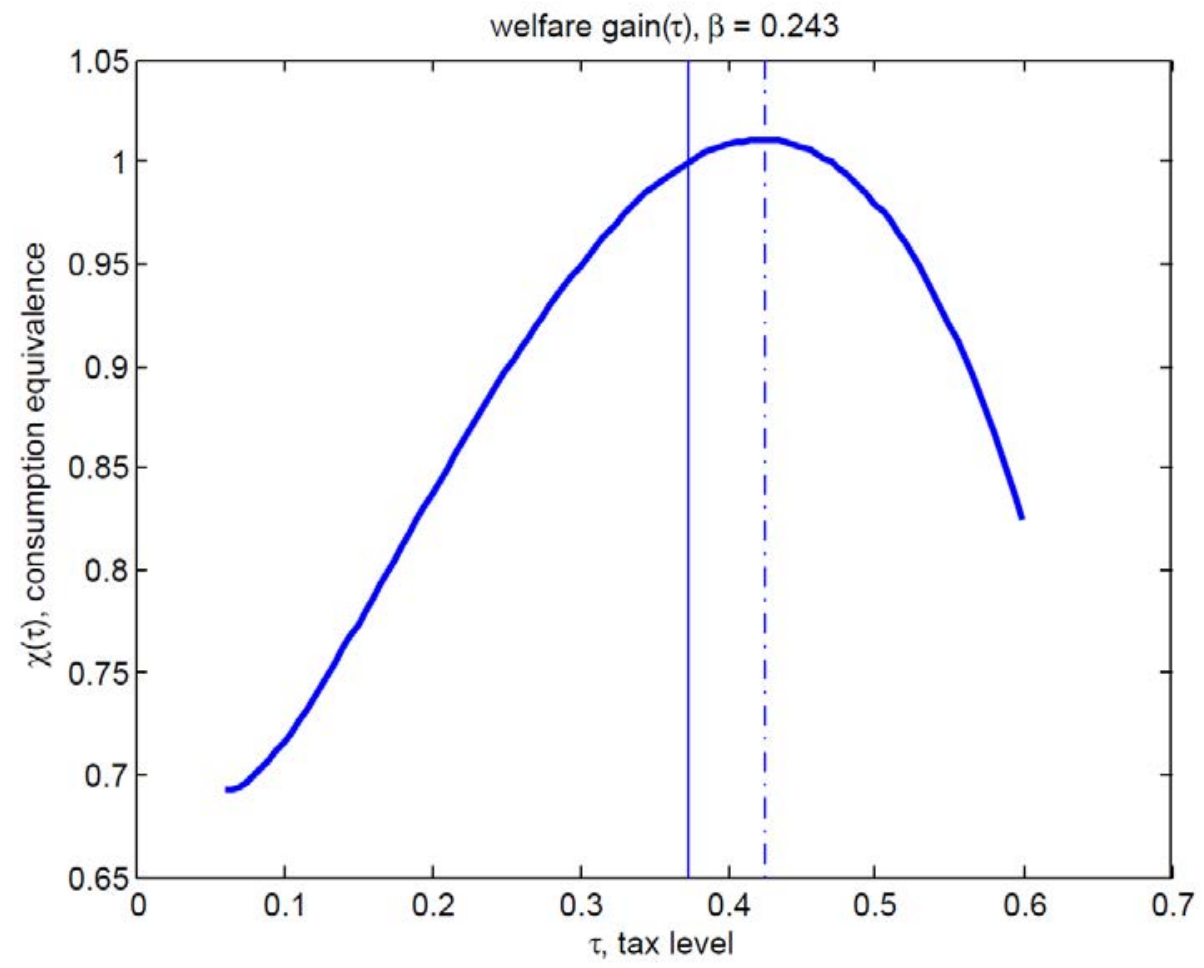

Figure 4: Consumption equivalence as a function of the corruption rate

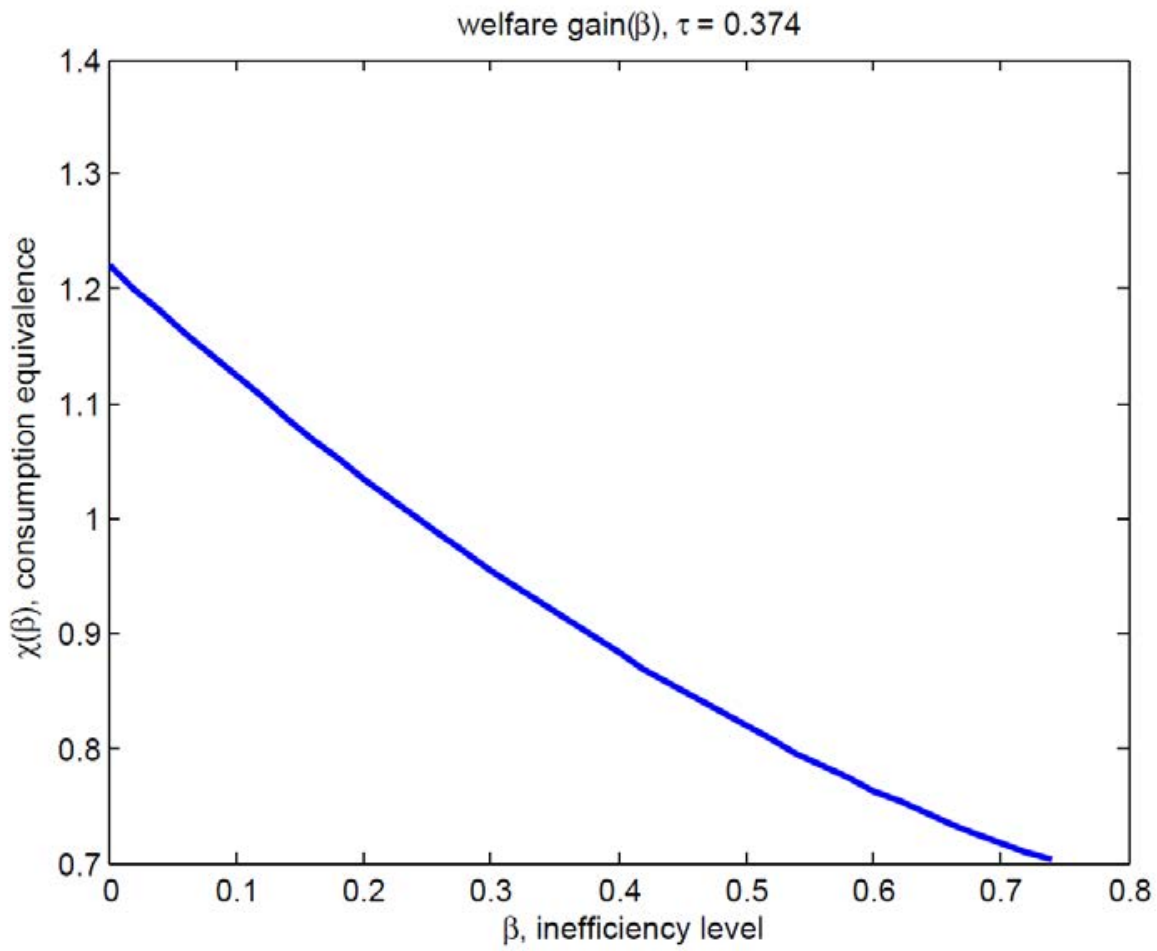


Figure 5: Firm size distribution as a function of the tax rate

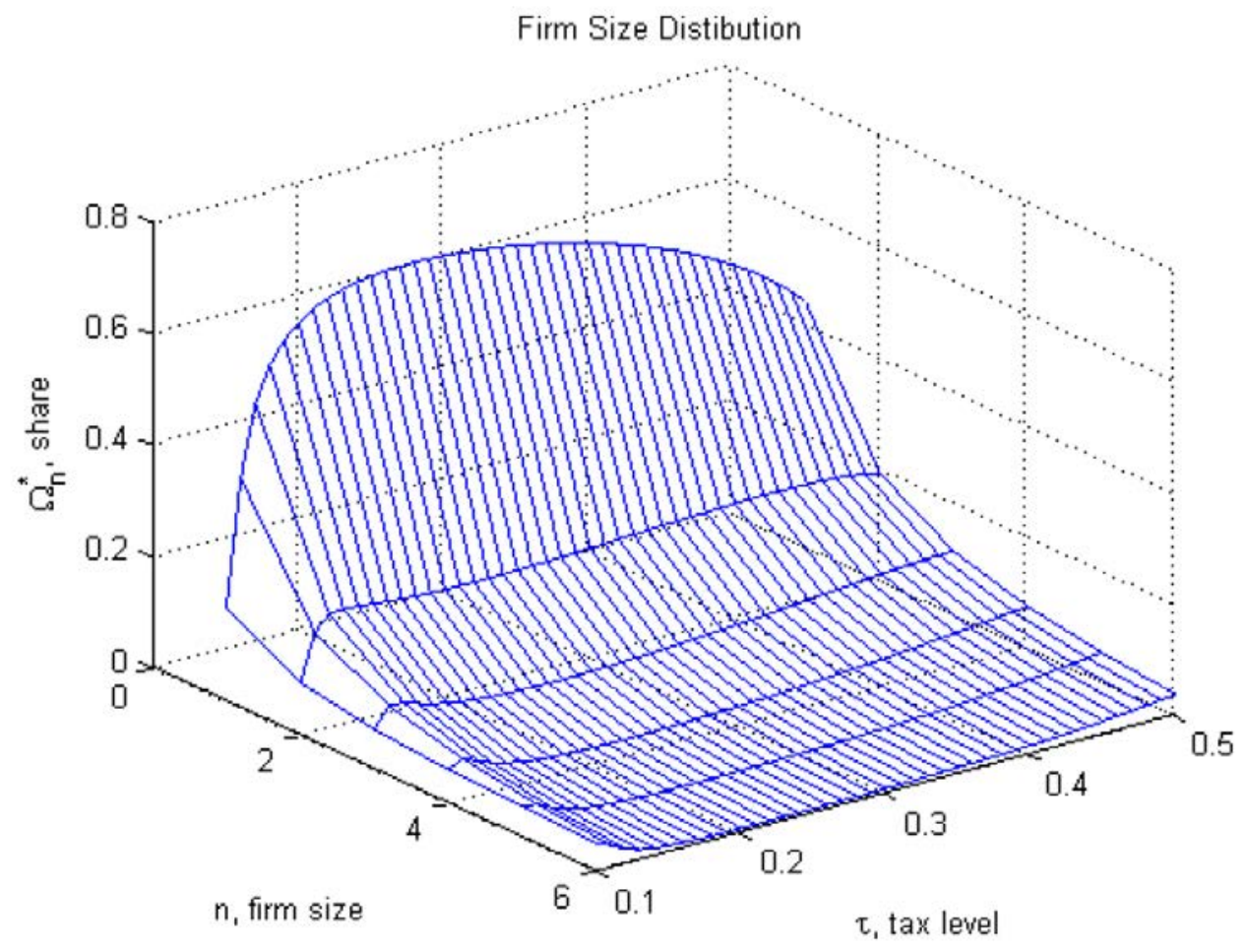

Figure 6: Average firm size as a function of the tax rate

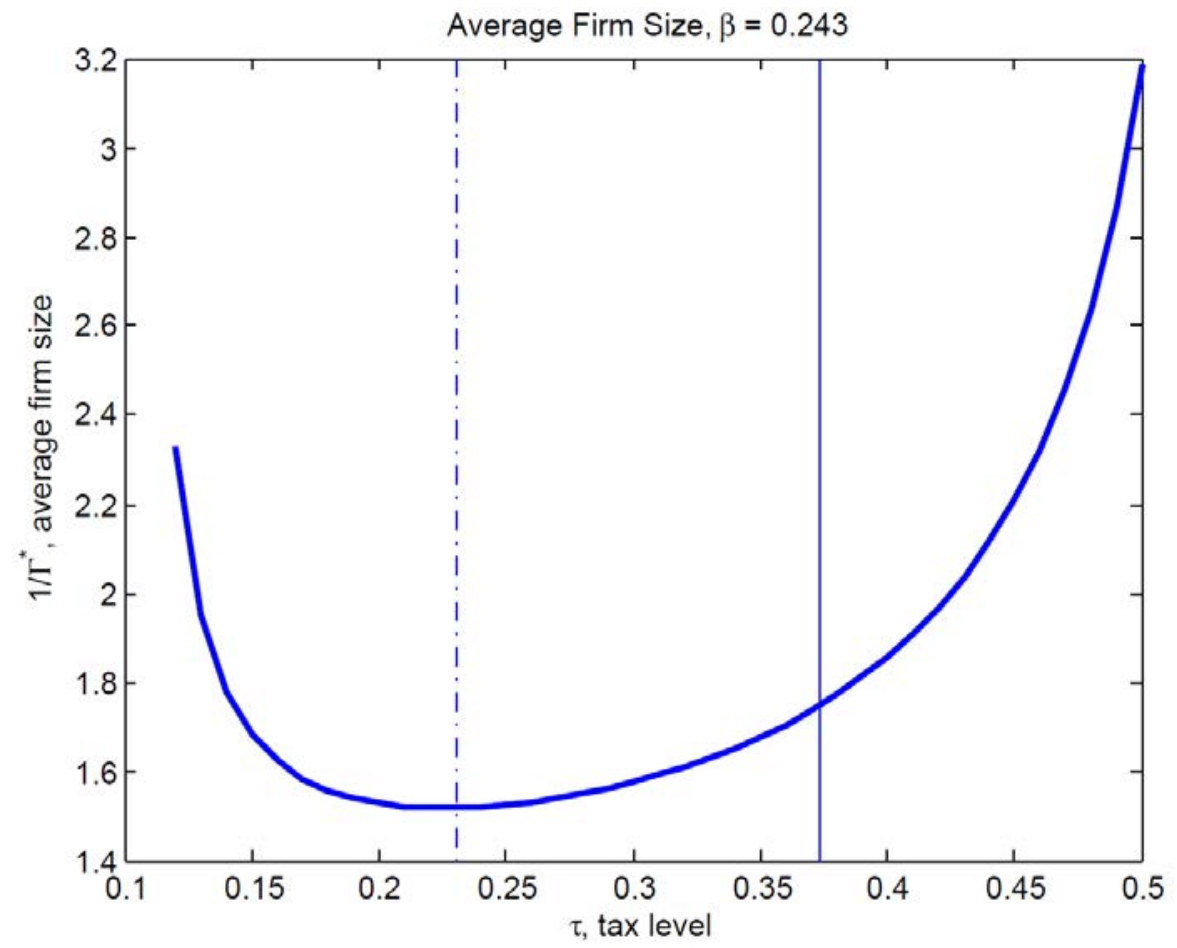


Figure 7: Entrant share of innovation as a function of the tax rate

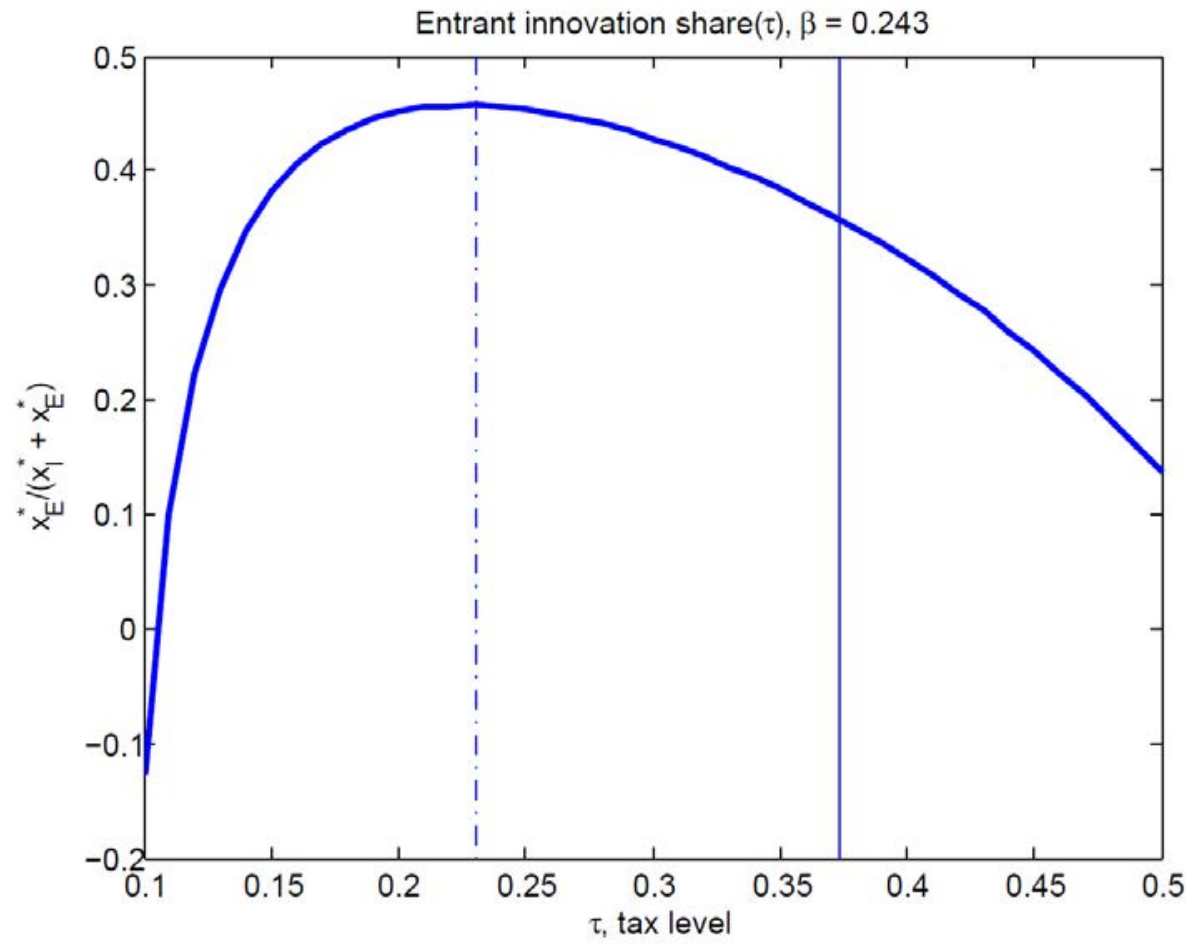




\begin{tabular}{|c|c|c|}
\hline & Mean & SD \\
\hline & $(1)$ & $(2)$ \\
\hline \multicolumn{3}{|l|}{ A. State analysis } \\
\hline State GDP (billions) & 167.46 & 214.85 \\
\hline State GDP per worker (thousands) & 69.77 & 19.96 \\
\hline Employment levels in LBD (millions, non-agriculture private-sector employer firms) & 2.29 & 2.44 \\
\hline Young establishments & 0.54 & 0.63 \\
\hline Old establishments & 1.76 & 1.83 \\
\hline Entering or exiting establishments & 0.25 & 0.29 \\
\hline Establishment counts in LBD (millions) & 0.12 & 0.13 \\
\hline Employment size of continuing establishments & 20.80 & 3.54 \\
\hline \multicolumn{3}{|l|}{ Log growth rates across periods with $1 \%$ winsorization } \\
\hline State GDP & 0.275 & 0.072 \\
\hline State GDP, deflated & 0.132 & 0.073 \\
\hline State GDP per worker & 0.194 & 0.060 \\
\hline State GDP per worker, deflated & 0.051 & 0.077 \\
\hline Employment & 0.081 & 0.063 \\
\hline Establishments & 0.074 & 0.051 \\
\hline State income tax revenues (billions) & 3.03 & 4.88 \\
\hline State income tax revenues per initial government expenditures & 0.16 & 0.07 \\
\hline Convictions of government officials & 17.7 & 22.2 \\
\hline \multicolumn{3}{|l|}{ B. County border analysis } \\
\hline Employment levels in LBD (thousands) & 38.22 & 136.60 \\
\hline Establishment counts in LBD (thousands) & 2.00 & 6.41 \\
\hline \multicolumn{3}{|l|}{ Log growth rates across periods with $1 \%$ winsorization } \\
\hline Employment & 0.086 & 0.128 \\
\hline Establishments & 0.077 & 0.091 \\
\hline Fraction of counties on state border & 0.38 & \\
\hline Fraction with more than $50 \%$ of economic activity within 100 -mi radius being within home state & 0.68 & \\
\hline
\end{tabular}

Notes: Panel A provides descriptive statistics for state-period estimations of taxation, corruption, and economic activity. The panel consists of 47 states with four time periods of five years each (1988-1992 to 2003-2007), using earlier and later years as appropriate for growth calculations. Variables are calculated as annual average for each five-year period. Panel B provides descriptive statistics for county-border analysis across the same four time periods. 
Table 2a: Panel relationship of taxation, corruption and state economic activity

\begin{tabular}{cccccccc}
$\begin{array}{c}\text { Base } \\
\text { estimation } \\
\text { with state and } \\
\text { time period } \\
\text { fixed effects }\end{array}$ & $\begin{array}{c}\text { Excluding } \\
\text { initial } \\
\text { employment } \\
\text { weights }\end{array}$ & $\begin{array}{c}\text { Including } \\
\text { period fixed } \\
\text { effects by } \\
\text { four census } \\
\text { regions }\end{array}$ & $\begin{array}{c}\text { Including } \\
\text { period fixed } \\
\text { effects by } \\
\text { nine census } \\
\text { divisions }\end{array}$ & $\begin{array}{c}\text { Including } \\
\text { time trends for } \\
\text { 1987 population, } \\
\text { patents, and } \\
\text { education levels }\end{array}$ & $\begin{array}{c}\text { Including } \\
\text { fixed effects } \\
\text { for period } x \\
\text { initial tax } \\
\text { quartile of state }\end{array}$ & $\begin{array}{c}\text { Including } \\
\text { lagged } \\
\text { state activity } \\
\text { in prior period }\end{array}$ & $\begin{array}{c}\text { Including } \\
\text { squared } \\
\text { taxation term } \\
\text { and corruption } \\
\text { interaction }\end{array}$ \\
\hline$(1)$ & $(2)$ & $(3)$ & $(4)$ & $(5)$ & $(6)$ & (7) & (8) \\
\hline
\end{tabular}

\begin{tabular}{|c|c|c|c|c|c|c|c|c|}
\hline \multirow[b]{2}{*}{$\begin{array}{l}\text { Log tax revenues per } \\
\text { gov. exp. in prior period }\end{array}$} & \multicolumn{8}{|c|}{ Dependent variable is log state GDP in period } \\
\hline & $\begin{array}{l}0.183^{*} \\
(0.096)\end{array}$ & $\begin{array}{l}0.140^{*} \\
(0.073)\end{array}$ & $\begin{array}{l}0.140 * * \\
(0.067)\end{array}$ & $\begin{array}{c}0.048 \\
(0.045)\end{array}$ & $\begin{array}{l}0.165^{*} \\
(0.082)\end{array}$ & $\begin{array}{l}0.171^{*} \\
(0.106)\end{array}$ & $\begin{array}{c}0.081 \\
(0.059)\end{array}$ & $\begin{array}{l}0.182^{*} \\
(0.096)\end{array}$ \\
\hline $\begin{array}{l}\text { Log tax revenues per } \\
\text { gov. exp. in prior period SQ }\end{array}$ & & & & & & & & $\begin{array}{l}-0.033 \\
(0.024)\end{array}$ \\
\hline $\begin{array}{l}\text { Log corruption per } \\
\text { gov. exp. in prior period }\end{array}$ & $\begin{array}{l}-0.017 \\
(0.015)\end{array}$ & $\begin{array}{l}-0.006 \\
(0.019)\end{array}$ & $\begin{array}{l}-0.014 \\
(0.015)\end{array}$ & $\begin{array}{l}-0.009 \\
(0.010)\end{array}$ & $\begin{array}{l}-0.018 \\
(0.014)\end{array}$ & $\begin{array}{l}-0.017 \\
(0.015)\end{array}$ & $\begin{array}{l}-0.012 \\
(0.012)\end{array}$ & $\begin{array}{l}-0.012 \\
(0.019)\end{array}$ \\
\hline $\begin{array}{l}\text { Interaction of taxes and } \\
\text { corruption in prior period }\end{array}$ & $\begin{array}{c}-0.060 * * \\
(0.023)\end{array}$ & $\begin{array}{l}-0.049 \\
(0.033)\end{array}$ & $\begin{array}{c}-0.055^{* *} \\
(0.022)\end{array}$ & $\begin{array}{c}-0.039 * * \\
(0.017)\end{array}$ & $\begin{array}{c}-0.053 * * * \\
(0.017)\end{array}$ & $\begin{array}{c}-0.053^{* *} \\
(0.020)\end{array}$ & $\begin{array}{c}-0.040 * * * \\
(0.013)\end{array}$ & $\begin{array}{l}-0.072 * \\
(0.040)\end{array}$ \\
\hline $\begin{array}{l}\text { Interaction of taxes and } \\
\text { corruption in prior pd. SQ }\end{array}$ & & & & & & & & $\begin{array}{l}-0.021 \\
(0.028)\end{array}$ \\
\hline $\begin{array}{l}\text { Log state GDP } \\
\text { in the prior period }\end{array}$ & & & & & & & $\begin{array}{c}0.465^{* * *} \\
(0.123)\end{array}$ & \\
\hline State and period effects & Yes & Yes & Yes & Yes & Yes & Yes & Yes & Yes \\
\hline Observations & 188 & 188 & 188 & 188 & 188 & 188 & 188 & 188 \\
\hline
\end{tabular}

Dependent variable is log state GDP in period 
Table 2b: Estimated marginal taxation effects for state GDP

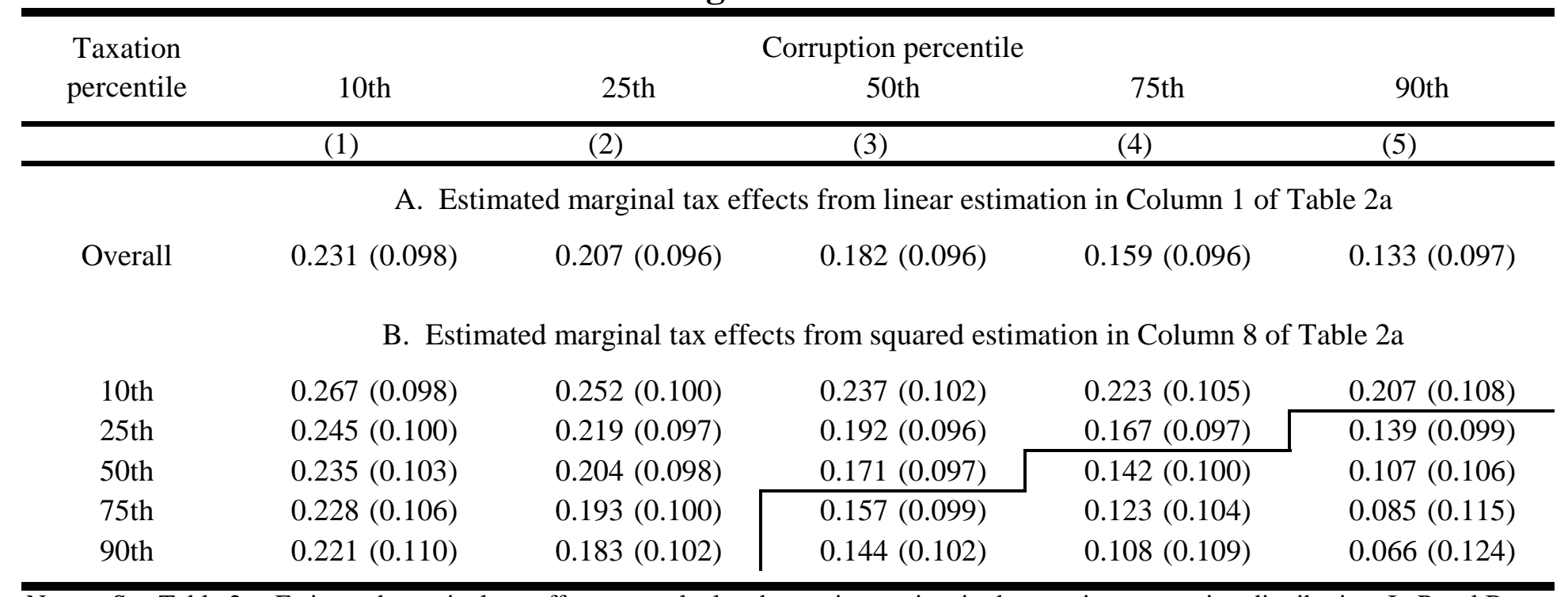

Notes: See Table 2a. Estimated marginal tax effects are calculated at various points in the taxation-corruption distribution. In Panel B, coefficients to the left and above the indicated line are statistically significant at a $10 \%$ level. 
Table 3a: Panel relationship of taxation, corruption and state growth

\begin{tabular}{|c|c|c|c|c|c|c|c|c|}
\hline & \multicolumn{2}{|c|}{$\begin{array}{l}\text { Log growth in } \\
\text { state GDP }\end{array}$} & \multicolumn{2}{|c|}{$\begin{array}{l}\text { Log growth in } \\
\text { state GDP per worker }\end{array}$} & \multicolumn{2}{|c|}{$\begin{array}{l}\text { Log growth in } \\
\text { state employment }\end{array}$} & \multicolumn{2}{|c|}{$\begin{array}{c}\text { Log growth in } \\
\text { state establishments }\end{array}$} \\
\hline & $(1)$ & $(2)$ & (3) & (4) & $(5)$ & (6) & $(7)$ & $(8)$ \\
\hline $\begin{array}{l}\text { Log tax revenues per } \\
\text { gov. exp. in prior period }\end{array}$ & $\begin{array}{c}0.082 \\
(0.059)\end{array}$ & $\begin{array}{c}0.082 \\
(0.059)\end{array}$ & $\begin{array}{l}0.030 * \\
(0.018)\end{array}$ & $\begin{array}{c}0.029 \\
(0.019)\end{array}$ & $\begin{array}{c}0.029 \\
(0.035)\end{array}$ & $\begin{array}{c}0.032 \\
(0.037)\end{array}$ & $\begin{array}{c}0.019 \\
(0.038)\end{array}$ & $\begin{array}{c}0.019 \\
(0.023)\end{array}$ \\
\hline $\begin{array}{l}\text { Log tax revenues per } \\
\text { gov. exp. in prior period SQ }\end{array}$ & & $\begin{array}{c}-0.032 * * * \\
(0.011)\end{array}$ & & $\begin{array}{l}-0.011 \\
(0.008)\end{array}$ & & $\begin{array}{l}-0.010 \\
(0.008)\end{array}$ & & $\begin{array}{l}-0.004 \\
(0.007)\end{array}$ \\
\hline $\begin{array}{l}\text { Log corruption per } \\
\text { gov. exp. in prior period }\end{array}$ & $\begin{array}{l}-0.011 \\
(0.012)\end{array}$ & $\begin{array}{l}-0.009 \\
(0.016)\end{array}$ & $\begin{array}{l}-0.009 \\
(0.008)\end{array}$ & $\begin{array}{l}-0.007 \\
(0.011)\end{array}$ & $\begin{array}{l}-0.001 \\
(0.009)\end{array}$ & $\begin{array}{c}0.000 \\
(0.012)\end{array}$ & $\begin{array}{l}-0.004 \\
(0.006)\end{array}$ & $\begin{array}{l}-0.003 \\
(0.010)\end{array}$ \\
\hline $\begin{array}{l}\text { Interaction of taxes and } \\
\text { corruption in prior period }\end{array}$ & $\begin{array}{c}-0.040 * * * \\
(0.013)\end{array}$ & $\begin{array}{l}-0.048 * \\
(0.029)\end{array}$ & $\begin{array}{l}-0.016 * * \\
(0.008)\end{array}$ & $\begin{array}{l}-0.022 \\
(0.016)\end{array}$ & $\begin{array}{c}-0.016 * * \\
(0.007)\end{array}$ & $\begin{array}{l}-0.019 \\
(0.018)\end{array}$ & $\begin{array}{c}-0.014 * * \\
(0.005)\end{array}$ & $\begin{array}{l}-0.016 \\
(0.014)\end{array}$ \\
\hline $\begin{array}{l}\text { Interaction of taxes and } \\
\text { corruption in prior period SQ }\end{array}$ & & $\begin{array}{l}-0.017 \\
(0.020)\end{array}$ & & $\begin{array}{l}-0.009 \\
(0.011)\end{array}$ & & $\begin{array}{l}-0.006 \\
(0.013)\end{array}$ & & $\begin{array}{l}-0.003 \\
(0.011)\end{array}$ \\
\hline $\begin{array}{l}\text { Lagged log state level } \\
\text { in the prior period }\end{array}$ & $\begin{array}{c}-0.533^{* * *} \\
(0.123)\end{array}$ & $\begin{array}{c}-0.537 * * * \\
(0.118)\end{array}$ & $\begin{array}{c}-0.656 * * * \\
(0.062)\end{array}$ & $\begin{array}{c}-0.639 * * * \\
(0.063)\end{array}$ & $\begin{array}{c}-0.410^{* * *} \\
(0.060)\end{array}$ & $\begin{array}{c}-0.423^{* * *} \\
(0.065)\end{array}$ & $\begin{array}{c}-0.371 * * * \\
(0.088)\end{array}$ & $\begin{array}{c}-0.372 * * * \\
(0.091)\end{array}$ \\
\hline State and period effects & Yes & Yes & Yes & Yes & Yes & Yes & Yes & Yes \\
\hline Observations & 188 & 188 & 188 & 188 & 188 & 188 & 188 & 188 \\
\hline
\end{tabular}

Notes: Estimations consider the panel relationship among taxation, corruption, and economic activity. The panel consists of 47 states with four time periods of five years each (1988-1992 to 2003-2007), using lagged values from prior periods. The dependent variables are log state growth rates indicated in column headers. The explanatory variable of interest is the interaction of lagged state income tax receipts and corruption (i.e., criminal convictions of public officials). Both metrics are normalized by initial state public expenditures and demeaned prior to interaction. Estimations weight by initial state employment, cluster standard errors by state, and include state and period fixed effects. There is less acceleration in economic growth following periods of high tax revenues when corruption is high. Marginal effects for Columns $1-4$ are presented in Tables 3b-3c. 
Table 3b: Est. marginal taxation effects for growth in state GDP

\begin{tabular}{cccccc}
\hline $\begin{array}{c}\text { Taxation } \\
\text { percentile }\end{array}$ & 10th & 25 th & Corruption percentile & 75th & 90th \\
\hline & $(1)$ & $(2)$ & (3) & (4) & (5) \\
\hline
\end{tabular}

A. Estimated marginal tax effects from linear estimation in Column 1 of Table 3a
Overall
$0.113(0.061)$
$0.098(0.060)$
$0.081(0.059)$
$0.066(0.058)$
$0.049(0.058)$

B. Estimated marginal tax effects from squared estimation in Column 2 of Table 3a

\begin{tabular}{llllll} 
10th & $0.151(0.062)$ & $0.143(0.062)$ & $0.136(0.062)$ & $0.129(0.063)$ & $0.121(0.064)$ \\
\cline { 5 - 6 } 25th & $0.126(0.061)$ & $0.109(0.060)$ & $0.092(0.059)$ & $0.076(0.060)$ & $0.057(0.062)$ \\
50th & $0.115(0.063)$ & $0.094(0.059)$ & $0.072(0.059)$ & $0.052(0.061)$ & $0.029(0.067)$ \\
75th & $0.107(0.064)$ & $0.083(0.059)$ & $0.058(0.059)$ & $0.035(0.064)$ & $0.008(0.073)$ \\
90th & $0.101(0.066)$ & $0.074(0.060)$ & $0.046(0.060)$ & $0.020(0.066)$ & $-0.010(0.079)$ \\
\cline { 6 - 7 }
\end{tabular}

Notes: See Table 3a. Estimated marginal tax effects are calculated at various points in the taxation-corruption distribution.

Table 3c: Est. marginal taxation effects for growth in state GDP per worker

\begin{tabular}{cccccc}
\hline $\begin{array}{c}\text { Taxation } \\
\text { percentile }\end{array}$ & 10 th & 25 th & Corruption percentile & 75th & 90th \\
\hline & $(1)$ & $(2)$ & $(3)$ & $(4)$ & (5) \\
\hline
\end{tabular}

A. Estimated marginal tax effects from linear estimation in Column 3 of Table 3a

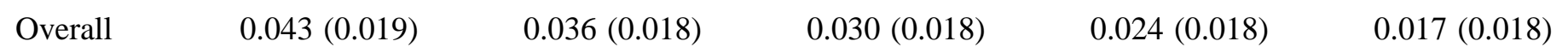

B. Estimated marginal tax effects from squared estimation in Column 4 of Table 3a

\begin{tabular}{llllllr} 
10th & $0.054(0.018)$ & $0.051(0.018)$ & $0.048(0.019)$ & $0.046(0.020)$ & $0.042(0.022)$ \\
\cline { 6 - 6 } 25th & $0.048(0.022)$ & $0.040(0.019)$ & $0.033(0.018)$ & $0.025(0.018)$ & $0.017(0.020)$ \\
50th & $0.045(0.025)$ & $0.035(0.021)$ & $0.025(0.020)$ & $0.016(0.021)$ & $0.006(0.025)$ \\
75th & $0.043(0.028)$ & $0.032(0.023)$ & $0.020(0.022)$ & $0.009(0.024)$ & $-0.003(0.030)$ \\
90th & $0.041(0.031)$ & $0.029(0.025)$ & $0.016(0.024)$ & $0.004(0.027)$ & $-0.010(0.035)$ \\
\cline { 2 - 3 }
\end{tabular}

Notes: See Table 3a. Estimated marginal tax effects are calculated at various points in the taxation-corruption distribution. 
Table 4: Growth estimations with covariates modelled

\begin{tabular}{|c|c|c|c|c|c|c|}
\hline & \multicolumn{3}{|c|}{ Log state GDP growth } & \multicolumn{3}{|c|}{ Log state GDP per worker growth } \\
\hline & $(1)$ & $(2)$ & (3) & $(4)$ & $(5)$ & $(6)$ \\
\hline $\begin{array}{l}\text { Log tax revenues per } \\
\text { gov. exp. in prior period }\end{array}$ & $\begin{array}{l}-0.011 \\
(0.008)\end{array}$ & $\begin{array}{l}-0.007 \\
(0.009)\end{array}$ & $\begin{array}{l}-0.002 \\
(0.007)\end{array}$ & $\begin{array}{l}0.009^{*} \\
(0.005)\end{array}$ & $\begin{array}{c}0.012 * * * \\
(0.004)\end{array}$ & $\begin{array}{l}0.012^{*} \\
(0.007)\end{array}$ \\
\hline $\begin{array}{l}\text { Log corruption per } \\
\text { gov. exp. in prior period }\end{array}$ & $\begin{array}{c}-0.016 * * \\
(0.008)\end{array}$ & $\begin{array}{l}-0.015^{*} \\
(0.008)\end{array}$ & $\begin{array}{l}-0.010 \\
(0.007)\end{array}$ & $\begin{array}{c}0.005 \\
(0.006)\end{array}$ & $\begin{array}{c}0.006 \\
(0.006)\end{array}$ & $\begin{array}{c}0.004 \\
(0.007)\end{array}$ \\
\hline $\begin{array}{l}\text { Interaction of taxes and } \\
\text { corruption in prior period }\end{array}$ & $\begin{array}{c}-0.021^{* * *} \\
(0.007)\end{array}$ & $\begin{array}{c}-0.022 * * * \\
(0.007)\end{array}$ & $\begin{array}{l}-0.013 \\
(0.008)\end{array}$ & $\begin{array}{c}-0.016 * * \\
(0.007)\end{array}$ & $\begin{array}{l}-0.013^{*} \\
(0.007)\end{array}$ & $\begin{array}{l}-0.013^{*} \\
(0.007)\end{array}$ \\
\hline $\begin{array}{l}\text { Lagged log state level } \\
\text { in the prior period }\end{array}$ & & $\begin{array}{l}-0.008^{*} \\
(0.004)\end{array}$ & $\begin{array}{l}-0.007 \\
(0.008)\end{array}$ & & $\begin{array}{c}-0.085^{* *} \\
(0.040)\end{array}$ & $\begin{array}{c}-0.241 * * * \\
(0.045)\end{array}$ \\
\hline Log January temperature & $\begin{array}{c}0.044 * * * \\
(0.012)\end{array}$ & $\begin{array}{c}0.053 * * * \\
(0.014)\end{array}$ & $\begin{array}{c}0.045^{* * *} \\
(0.013)\end{array}$ & $\begin{array}{c}0.023^{* * *} \\
(0.006)\end{array}$ & $\begin{array}{c}0.033^{* * *} \\
(0.008)\end{array}$ & $\begin{array}{c}0.045^{* * *} \\
(0.008)\end{array}$ \\
\hline Log bachelor's education share & $\begin{array}{l}0.057^{*} \\
(0.028)\end{array}$ & $\begin{array}{l}0.060 * * \\
(0.028)\end{array}$ & $\begin{array}{c}0.037 \\
(0.043)\end{array}$ & $\begin{array}{l}0.100 * * * \\
(0.020)\end{array}$ & $\begin{array}{c}0.138 * * * \\
(0.027)\end{array}$ & $\begin{array}{c}0.149 * * * \\
(0.033)\end{array}$ \\
\hline $\begin{array}{l}\text { Period fixed effects } \\
\text { Additional controls }\end{array}$ & Yes & Yes & $\begin{array}{l}\text { Yes } \\
\text { Yes }\end{array}$ & Yes & Yes & $\begin{array}{l}\text { Yes } \\
\text { Yes }\end{array}$ \\
\hline Observations & 180 & 180 & 180 & 180 & 180 & 180 \\
\hline
\end{tabular}

Notes: See Table 3a. Estimations exclude state fixed effects and instead model growth covariates. Additional covariates control for housing prices, population density, Bartik-style growth projections for employment using the initial industry distribution interacted with national growth by industry, and the housing supply elasticity of cities measured by Saiz (2010) through geographic features of cities. 
Table 5: Panel relationship of taxation, corruption and economic activity

\begin{tabular}{|c|c|c|c|c|c|c|}
\hline & $\begin{array}{l}\text { Log total } \\
\text { employment } \\
\text { in young } \\
\text { establishments } \\
\text { in period }\end{array}$ & $\begin{array}{l}\text { Log total } \\
\text { employment } \\
\text { in old } \\
\text { establishments } \\
\text { in period }\end{array}$ & $\begin{array}{c}\text { Log total } \\
\text { employment } \\
\text { in entry/exit } \\
\text { establishments } \\
\text { in period }\end{array}$ & $\begin{array}{l}\text { Log average } \\
\text { size of } \\
\text { continuing } \\
\text { establishments } \\
\text { in period }\end{array}$ & $\begin{array}{l}\text { Log patenting } \\
\text { of individuals } \\
\text { and firms that } \\
\text { are younger } \\
\text { than five years }\end{array}$ & $\begin{array}{l}\text { Log patenting } \\
\text { of incumbent } \\
\text { firms that are } \\
\text { five years old } \\
\text { or more }\end{array}$ \\
\hline & $(1)$ & $(2)$ & $(3)$ & $(4)$ & $(5)$ & $(6)$ \\
\hline $\begin{array}{l}\text { Log tax revenues per } \\
\text { gov. exp. in prior period }\end{array}$ & $\begin{array}{c}0.088 \\
(0.110)\end{array}$ & $\begin{array}{c}0.160 \\
(0.120)\end{array}$ & $\begin{array}{c}0.092 \\
(0.130)\end{array}$ & $\begin{array}{c}0.049 \\
(0.032)\end{array}$ & $\begin{array}{c}0.085 \\
(0.137)\end{array}$ & $\begin{array}{c}0.115 \\
(0.280)\end{array}$ \\
\hline $\begin{array}{l}\text { Log corruption per } \\
\text { gov. exp. in prior period }\end{array}$ & $\begin{array}{c}0.005 \\
(0.015)\end{array}$ & $\begin{array}{l}-0.008 \\
(0.015)\end{array}$ & $\begin{array}{c}0.007 \\
(0.018)\end{array}$ & $\begin{array}{c}0.004 \\
(0.006)\end{array}$ & $\begin{array}{c}0.003 \\
(0.038)\end{array}$ & $\begin{array}{l}-0.086 \\
(0.085)\end{array}$ \\
\hline $\begin{array}{l}\text { Interaction of taxes and } \\
\text { corruption in prior period }\end{array}$ & $\begin{array}{c}-0.043^{* * *} \\
(0.015)\end{array}$ & $\begin{array}{c}-0.055^{* *} \\
(0.025)\end{array}$ & $\begin{array}{c}-0.045^{* *} \\
(0.018)\end{array}$ & $\begin{array}{l}-0.014 \\
(0.010)\end{array}$ & $\begin{array}{c}-0.092 * * \\
(0.037)\end{array}$ & $\begin{array}{l}-0.075 \\
(0.076)\end{array}$ \\
\hline State and period effects & Yes & Yes & Yes & Yes & Yes & Yes \\
\hline Observations & 188 & 188 & 188 & 188 & 188 & 188 \\
\hline
\end{tabular}

Notes: See Table 2a. Column 1 of Table 2a is repeated for various economic outcomes. 
Table 6: Lead/lag test of panel relationship

\begin{tabular}{lcccc}
\hline & $\begin{array}{c}\text { Log state } \\
\text { GDP } \\
\text { in prior period }\end{array}$ & $\begin{array}{c}\text { Log state } \\
\text { employment } \\
\text { in prior period }\end{array}$ & $\begin{array}{c}\text { Log state } \\
\text { GDP growth } \\
\text { in prior period }\end{array}$ & $\begin{array}{c}\text { Log state } \\
\text { employment } \\
\text { growth } \\
\text { in prior period }\end{array}$ \\
\cline { 2 - 5 } & $(1)$ & $(2)$ & $(3)$ & $(4)$ \\
\hline Log tax revenues per & 0.058 & 0.091 & -0.051 & -0.061 \\
gov. exp. in current period & $(0.113)$ & $(0.155)$ & $(0.196)$ & $(0.148)$ \\
Log corruption per & 0.006 & 0.008 & 0.026 & 0.024 \\
gov. exp. in current period & $(0.029)$ & $(0.032)$ & $(0.033)$ & $(0.029)$ \\
Interaction of taxes and & $\mathbf{- 0 . 0 0 1}$ & $\mathbf{0 . 0 0 3}$ & $\mathbf{0 . 0 1 3}$ & $\mathbf{0 . 0 3 9}$ \\
corruption in current period & $\mathbf{( 0 . 0 4 4 )}$ & $\mathbf{( 0 . 0 5 5 )}$ & $\mathbf{( 0 . 0 5 0 )}$ & $\mathbf{( 0 . 0 2 9 )}$ \\
State and period effects & Yes & Yes & Yes & Yes \\
Observations & 141 & 141 & 94 & 94
\end{tabular}

Notes: See Tables 2a and 3a. Columns 1 and 2 consider lagged state GDP and employment on current tax revenues and corruption akin to a Granger causality test. Columns 3 and 4 consider lagged state GDP and employment growth and control for the lagged level two periods before. 
Table 7a: Panel relationship of taxation, corruption and growth in county employment

\begin{tabular}{|c|c|c|c|c|c|c|c|}
\hline & \multirow[b]{2}{*}{$\begin{array}{l}\text { Base estimation } \\
\text { using } 100 \text { mile } \\
\text { spatial ring } \\
\text { around county }\end{array}$} & \multicolumn{4}{|c|}{ Disaggregating the county sample around state borders } & \multirow[b]{2}{*}{$\begin{array}{l}\text { Narrowing } \\
\text { spatial range } \\
\text { from } 100 \text { miles } \\
\text { to } 50 \text { miles } \\
\text { around county }\end{array}$} & \multirow[b]{2}{*}{$\begin{array}{l}\text { Widening } \\
\text { spatial range } \\
\text { from } 100 \text { miles } \\
\text { to } 200 \text { miles } \\
\text { around county }\end{array}$} \\
\hline & & $\begin{array}{l}\text { Counties that } \\
\text { border other } \\
\text { states }\end{array}$ & $\begin{array}{c}\text { Counties that } \\
\text { do not border } \\
\text { other states }\end{array}$ & $\begin{array}{c}\text { Counties with } \\
>50 \% \text { of local } \\
\text { employment } \\
\text { in other states }\end{array}$ & $\begin{array}{c}\text { Counties with } \\
<50 \% \text { of local } \\
\text { employment } \\
\text { in other states }\end{array}$ & & \\
\hline & $(1)$ & $(2)$ & $(3)$ & $(4)$ & (5) & $(6)$ & $(7)$ \\
\hline & \multicolumn{7}{|c|}{ Dependent variable is log growth in county employment } \\
\hline $\begin{array}{l}\text { Log tax revenues per } \\
\text { gov. exp. in prior period }\end{array}$ & $\begin{array}{c}0.046 \\
(0.047)\end{array}$ & $\begin{array}{c}0.074 \\
(0.053)\end{array}$ & $\begin{array}{c}0.046 \\
(0.053)\end{array}$ & $\begin{array}{c}0.028 \\
(0.098)\end{array}$ & $\begin{array}{c}0.050 \\
(0.046)\end{array}$ & $\begin{array}{c}0.034 \\
(0.037)\end{array}$ & $\begin{array}{c}0.014 \\
(0.051)\end{array}$ \\
\hline $\begin{array}{l}\text { Log corruption per } \\
\text { gov. exp. in prior period }\end{array}$ & $\begin{array}{c}0.009 \\
(0.014)\end{array}$ & $\begin{array}{c}0.021 \\
(0.016)\end{array}$ & $\begin{array}{c}0.006 \\
(0.015)\end{array}$ & $\begin{array}{l}0.038^{*} \\
(0.021)\end{array}$ & $\begin{array}{c}0.005 \\
(0.013)\end{array}$ & $\begin{array}{c}0.005 \\
(0.011)\end{array}$ & $\begin{array}{c}0.007 \\
(0.019)\end{array}$ \\
\hline $\begin{array}{l}\text { Interaction of taxes and } \\
\text { corruption in prior period }\end{array}$ & $\begin{array}{c}-0.032 * * \\
(0.013)\end{array}$ & $\begin{array}{l}-0.036 \\
(0.024)\end{array}$ & $\begin{array}{c}-0.035^{* *} \\
(0.014)\end{array}$ & $\begin{array}{c}-0.056 * * \\
(0.026)\end{array}$ & $\begin{array}{c}-0.035^{* * *} \\
(0.013)\end{array}$ & $\begin{array}{c}-0.022 * * \\
(0.009)\end{array}$ & $\begin{array}{c}-0.047 * * \\
(0.021)\end{array}$ \\
\hline $\begin{array}{l}\text { Lagged log county level } \\
\text { in the prior period }\end{array}$ & $\begin{array}{c}-0.394^{* * *} \\
(0.023)\end{array}$ & $\begin{array}{c}-0.347^{* * *} \\
(0.033)\end{array}$ & $\begin{array}{c}-0.428 * * * \\
(0.028)\end{array}$ & $\begin{array}{c}-0.353^{* * *} \\
(0.038)\end{array}$ & $\begin{array}{c}-0.403^{* * *} \\
(0.027)\end{array}$ & $\begin{array}{c}-0.395^{* * *} \\
(0.024)\end{array}$ & $\begin{array}{c}-0.392 * * * \\
(0.024)\end{array}$ \\
\hline County and period effects & Yes & Yes & Yes & Yes & Yes & Yes & Yes \\
\hline Observations & 11,180 & 4,216 & 6,964 & 2,853 & 8,327 & 11,180 & 11,180 \\
\hline
\end{tabular}


Table 7b: Panel relationship of taxation, corruption and growth in county establishments

\begin{tabular}{|c|c|c|c|c|c|c|c|}
\hline & \multirow[b]{2}{*}{$\begin{array}{l}\text { Base estimation } \\
\text { using } 100 \text { mile } \\
\text { spatial ring } \\
\text { around county }\end{array}$} & \multicolumn{4}{|c|}{ Disaggregating the county sample around state borders } & \multirow[b]{2}{*}{$\begin{array}{l}\text { Narrowing } \\
\text { spatial range } \\
\text { from } 100 \text { miles } \\
\text { to } 50 \text { miles } \\
\text { around county }\end{array}$} & \multirow[b]{2}{*}{$\begin{array}{l}\text { Widening } \\
\text { spatial range } \\
\text { from } 100 \text { miles } \\
\text { to } 200 \text { miles } \\
\text { around county }\end{array}$} \\
\hline & & $\begin{array}{c}\text { Counties that } \\
\text { border other } \\
\text { states }\end{array}$ & $\begin{array}{l}\text { Counties that } \\
\text { do not border } \\
\text { other states }\end{array}$ & $\begin{array}{l}\text { Counties with } \\
>50 \% \text { of local } \\
\text { employment } \\
\text { in other states }\end{array}$ & $\begin{array}{l}\text { Counties with } \\
<50 \% \text { of local } \\
\text { employment } \\
\text { in other states }\end{array}$ & & \\
\hline & $(1)$ & $(2)$ & $(3)$ & $(4)$ & $(5)$ & $(6)$ & $(7)$ \\
\hline & \multicolumn{7}{|c|}{ Dependent variable is log growth in county establishments } \\
\hline $\begin{array}{l}\text { Log tax revenues per } \\
\text { gov. exp. in prior period }\end{array}$ & $\begin{array}{c}0.073 * * \\
(0.031)\end{array}$ & $\begin{array}{l}0.084 * * \\
(0.037)\end{array}$ & $\begin{array}{c}0.068 * * \\
(0.033)\end{array}$ & $\begin{array}{l}0.084^{*} \\
(0.047)\end{array}$ & $\begin{array}{l}0.066 * * \\
(0.030)\end{array}$ & $\begin{array}{l}0.043^{*} \\
(0.025)\end{array}$ & $\begin{array}{c}0.038 \\
(0.038)\end{array}$ \\
\hline $\begin{array}{l}\text { Log corruption per } \\
\text { gov. exp. in prior period }\end{array}$ & $\begin{array}{c}0.002 \\
(0.010)\end{array}$ & $\begin{array}{c}0.007 \\
(0.010)\end{array}$ & $\begin{array}{c}0.001 \\
(0.011)\end{array}$ & $\begin{array}{c}0.026 \\
(0.018)\end{array}$ & $\begin{array}{l}-0.003 \\
(0.010)\end{array}$ & $\begin{array}{c}0.000 \\
(0.008)\end{array}$ & $\begin{array}{l}-0.004 \\
(0.013)\end{array}$ \\
\hline $\begin{array}{l}\text { Interaction of taxes and } \\
\text { corruption in prior period }\end{array}$ & $\begin{array}{c}-0.025 * * * \\
(0.008)\end{array}$ & $\begin{array}{c}-0.042^{* * *} \\
(0.014)\end{array}$ & $\begin{array}{c}-0.021 * * \\
(0.008)\end{array}$ & $\begin{array}{l}-0.048 \\
(0.033)\end{array}$ & $\begin{array}{c}-0.023^{* * *} \\
(0.008)\end{array}$ & $\begin{array}{c}-0.015^{* * *} \\
(0.006)\end{array}$ & $\begin{array}{c}-0.033^{* *} \\
(0.015)\end{array}$ \\
\hline $\begin{array}{l}\text { Lagged log county level } \\
\text { in the prior period }\end{array}$ & $\begin{array}{c}-0.316^{* * *} \\
(0.036)\end{array}$ & $\begin{array}{c}-0.325^{* * *} \\
(0.037)\end{array}$ & $\begin{array}{c}-0.309 * * * \\
(0.042)\end{array}$ & $\begin{array}{c}-0.337 * * * \\
(0.038)\end{array}$ & $\begin{array}{c}-0.297 * * * \\
(0.045)\end{array}$ & $\begin{array}{c}-0.315^{* * *} \\
(0.038)\end{array}$ & $\begin{array}{c}-0.312 * * * \\
(0.037)\end{array}$ \\
\hline County and period effects & Yes & Yes & Yes & Yes & Yes & Yes & Yes \\
\hline Observations & 11,180 & 4,216 & 6,964 & 2,853 & 8,327 & 11,180 & 11,180 \\
\hline
\end{tabular}

Notes: See Table 7a. The dependent variable is adjusted in these specifications to be log growth in county establishments. 